\title{
Abundance and Distribution of Mangrove Landbirds in Florida
}

\author{
John D. Lloyd,* Gary L. Slater \\ J.D. Lloyd \\ Ecostudies Institute, P.O. Box 106, South Strafford, Vermont 05070 \\ G.L. Slater \\ Ecostudies Institute, P.O. Box 703, Mount Vernon, Washington 98273
}

\begin{abstract}
Florida's mangroves provide habitat for an eclectic mix of bird species, including five taxa rarely found elsewhere in North America. Litule is known of the natural history of any of these birds, which poses an obstacle to effective conservation. To help fill some of the basic gaps in our understanding of this avifauna, we conducted extensive surveys in Florida's mangroves during 20082011 , with the goals of quantifying distribution and estimating breeding-season abundance of mangrove landbirds. We detected 80 species in the mangroves during the breeding season; most were species in Passeriformes $(n=29)$, but other important taxa included Ciconiiformes $(n=13)$ and Charadriiformes $(n=12)$. We focused our analysis on the 18 landbird species (including members of Falconiformes, Columbiformes, Cuculiformes, Piciformes, and Passeriformes) that had $>90$ detections and that were detected at $>5 \%$ of the survey points. The landbird avifauna of Florida's mangroves is lower in both species richness and total number of individuals than other vegetation types of southern Florida. The breeding assemblage of mangrove landbirds was dominated numerically by four species that accounted for $58 \%$ of all detections of landbirds (this same group accounted for $52 \%$ of detections of all species encountered): red-bellied woodpecker Melanerpes carolinus, northern cardinal Cardinalis cardinalis, Florida prairie warbler Selophaga discolor paludicola, and white-eyed vireo Vireo griseus. Only Florida prairie warbler is restricted to mangroves; the other three species are common throughout much of eastern North America. Each of these species was also widely distributed in the mangroves. Of the other species unique to the mangroves of Florida, black-whiskered vireo Vireo alliloquus was widespread but was less abundant than Florida prairie warbler. White-crowned pigeon Palagioenas leucocephala, gray kingbird Tyrannus dominicensis, and Cuban yellow warbler Setophaga petechia gundlachi were detected only in the Florida Keys and on the islands of Florida Bay, but were found in high densities where present. Mangrove cuckoo Coccyzus minor was found throughout the mangroves but occurred at very low density and at only a small percentage of survey points. Overall, mangrove landbirds reflect the biogeographic condition common throughout southern Florida, in which largely temperate faunas coexist with largely tropical floras. The predominance of temperate species in Florida's mangroves has produced an avifauna apparently more species-rich than that found in the mangroves of West Indian islands, which include additional tropical species but no species of temperate origin.
\end{abstract}

Keywords: black-whiskered vireo; Cuban yellow warbler; Florida prairie warbler; gray kingbird; mangrove cuckoo; mangroves; white-crowned pigeon

Received: August 31, 2012; Accepted: February 20, 2014; Published Online Early: April 2014; Published: May 2014

Citation: Lloyd JD, Slater GL. 2014. Abundance and Distribution of Mangrove Landbirds in Florida. North American Fauna 80:1-45. doi:10.3996/nafa.80.0001

Copyright: All material appearing in North American Fauna is in the public domain and may be reproduced or copied without permission unless specifically noted with the copyright symbol (c). Citation of the source, as given above, is requested.

The findings and conclusions in this article are those of the author(s) and do not necessarily represent the views of the U.S. Fish and Wildlife Service.

* Corresponding author: jlloyd@ecoinst.org

Subject Editor: Scott Robinson, Florida Museum of Natural History 


\section{Introduction}

Mangrove forests fringe the southern coast of Florida. From the open shrublands of stunted red mangrove Rhizophora mangle that penetrate inland to the edge of the Everglades to the tall, closed-canopy forests of the southwestern coast, Florida's mangroves take on a variety of forms. They are unified only in that they share a common assemblage of woody plants: red mangrove, black mangrove Avicennia germinans, white mangrove Laguncularia racemosa, and buttonwood Conocarpus erectus, either alone or in mixed-species assemblages. Diflicult to access even today, mangroves have long been shrouded in an air of mystery and danger (e.g., Iugo and Snedaker 1974). As one of the only truly tropical vegetation types in the continental United States, mangroves have attracted much attention from ecologists and naturalists. Farly research identified several key ecosystem services provided by mangroves, notably acting as the basal node in food webs that support sport and commercial fisheries (Heald and Odum 1970) and in protecting shorelines (Davis 1940, 1943), which in turn generated substantial interest in conducting ecological research on Florida's mangroves (Snedaker 1989).

One facet that has largely escaped investigation, however, is the faunal assemblages of Florida's mangrove ecosystems (Snedaker 1989). Mangroves have been slow in revealing the lives of their inhabitants. Indeed, with the exception of fishes and some aquatic invertebrates, about which much is known (e.g., Odum and Heald 1972; Odum et al. 1982), information about other animals that inhabit mangroves, especially terrestrial animals, is limited largely to lists of species that use mangroves during some portion of their life cycle (e.g., Odum et al. 1982). That so litule is known of the terrestrial vertebrates inhabiting Florida's mangroves is somewhat surprising given the contribution that they make to the biological diversity of the continental United States. Consider, for example, the breeding landbirds of Florida's mangroves. In addition to several widely distributed species, this group includes five taxa rarely found elsewhere in North America: white-crowned pigeon, mangrove cuckoo, blackwhiskered vireo, Cuban yellow warbler, and Florida prairie warbler (scientific names appear in Table 1). A sixth species, gray kingbird, reaches its greatest abundance in the mangroves of Florida, but also occurs in urban areas of southern Florida and in other coastal forests farther north (Smith and Jackson 2002). Despite the significance of this group of species from the standpoint of the avifaunal diversity of North America, very litule is known about them.

The limited literature concerning mangrove landbirds has focused primarily on descriptions of natural history and population ecology. Of the mangrove endemics, white-crowned pigeon has received the most study (Bancroft and Bowman 1994; Strong and Bancroft 1994; Bancroft et al. 2000), although much basic information on the natural history of this species stems from Puerto Rico, where its habitats appear markedly different from those of Florida populations (Wiley and Wiley 1979). A series of studies conducted by Prather and Cruz (1995, 1996, 2002, 2006) yielded information on the breeding biology of populations of Florida prairie warblers, Cuban yellow warblers, and several other species at Key Largo and Sanibel Island, and Buerkle $(1999,2000)$ provided information on the genetics, morphology, and possible origin of Florida prairie warbler. The natural history of the other mangrove endemics or near-endemics is mostly undescribed, or is based on study of populations from the West Indies (e.g., Hughes 1997).

No quantitative descriptions of the structure of the breeding-season landbird assemblage across Florida's mangroves exist. Some information on distribution can be gleaned from the Florida Breeding Bird Allas (Woolfenden and Robertson 2006) or from general reference sources on the birdlife of Florida (e.g., Stevenson and Anderson 1994). Fstimates of abundance are almost totally lacking. Robertson (1955: 426) conducted surveys in the shrubby mangroves on North Nest Key in Florida Bay and visited the tall, riverine mangrove forests near Shark River, in present-day Everglades National Park, but he described the latter as "entirely birdless." Robertson and Kushlan (1974) used existing information to describe the structure of the mangrove avifauna, but the list was based more on anecdote and casual observation than the results of designed surveys.

One important consequence of knowing little about mangrove landbirds is that it stymies efforts to conserve their populations. Our lack of knowledge hinders our ability both to recognize and quantify current or future threats and to craft scientifically defensible conservation strategies. How, for example, do we identify where scarce resources for conservation should be allocated if we do not have a clear understanding of the distribution of the species we seek to conserve? Likewise, how can we assess the status, or implement protective actions, for a species whose abundance is unknown? Not surprisingly, both Partners in Flight and the U.S. Department of the Interior have identified mangrove landbirds as a priority for research and monitoring (Donovan et al. 2002; U.S. Department of the Interior 2005). The need for good information about all of the components of mangrove ecosystems, including birds, will only increase because mangroves in the United States face a host of threats to their existence: more intense or frequent tropical storms, sea-level rise, and changes in freshwater flows, among others (Doyle et al. 2003). 
Table 1. Number of individual birds detected during breeding-season surveys conducted from 2008 to 2011 at 354 locations in mangroves of Florida.

\begin{tabular}{|c|c|c|c|}
\hline Common name & Scientific name & Total counted & Mangrove landbird? \\
\hline Red-bellied woodpecker & Melanerpes carolinus & 2,371 & Yes \\
\hline Northern cardinal & Cardinalis cardinalis & 1,930 & Yes \\
\hline Prairie warbler & Setophaga discolor paludicola & 1,596 & Yes \\
\hline White-eyed vireo & Vireo griseus & 1,501 & Yes \\
\hline Red-winged blackbird & Agelaius phoeniceus & 1,029 & Yes \\
\hline Great crested flycatcher & Myiarchus crinitus & 770 & Yes \\
\hline American crow & Corvus brachyrhynchos & 625 & Yes \\
\hline White ibis & Eudocimus albus & 609 & No \\
\hline Pileated woodpecker & Dryocopus pileatus & 560 & Yes \\
\hline White-crowned pigeon & Patagioenas leucocephala & 468 & Yes \\
\hline Black-whiskered vireo & Vireo altiloquus & 436 & Yes \\
\hline Gray kingbird & Tyrannus dominicensis & 208 & Yes \\
\hline Red-shouldered hawk & Buteo lineatus extimus & 188 & Yes \\
\hline Carolina wren & Thryothorus ludovicianus & 164 & Yes \\
\hline Osprey & Pandion haliaetus & 151 & $\mathrm{No}^{\mathrm{a}}$ \\
\hline Yellow warbler & Setophaga petechia gundiachi & 147 & Yes \\
\hline Mourning dove & Zenaida macroura & 136 & Yes \\
\hline Double-crested cormorant & Phalacrocorax auritus & 127 & No \\
\hline Mangrove cuckoo & Coccyzus minor & 124 & Yes \\
\hline Common yellowthroat & Geothlypis trichas & 99 & Yes \\
\hline Common grackle & Quiscalus quiscula & 90 & Yes \\
\hline Eastern towhee & Pipilo erythrophthalmus & 55 & Yes \\
\hline Blue jay & Cyanocitta cristata & 49 & Yes \\
\hline Laughing gull & Leucophaeus atricilla & 49 & No \\
\hline Great blue heron & Ardea herodias herodias & 45 & No \\
\hline Great egret & Ardea alba & 43 & No \\
\hline Brown pelican & Pelecanus occidentalis & 42 & No \\
\hline Green heron & Butorides virescens & 41 & No \\
\hline Tricolored heron & Egretta tricolor & 39 & No \\
\hline Northern mockingbird & Mimus polyglottos & 38 & Yes \\
\hline Eurasian collared-dove & Streptopelia decaocto & 36 & Yes \\
\hline Swallow-tailed kite & Elanoides forficatus & 36 & Yes \\
\hline Common ground-dove & Columbina passerina & 33 & Yes \\
\hline Yellow-billed cuckoo & Coccyzus americanus & 29 & Yes \\
\hline Barred owl & Strix varia & 26 & Yes \\
\hline Black-necked stilt & Himantopus mexicanus & 26 & No \\
\hline Clapper rail & Rallus longirostris & 19 & No \\
\hline Turkey vulture & Cathartes aura & 18 & No \\
\hline Brown-headed cowbird & Molothrus ater & 15 & Yes \\
\hline American redstart & Setophaga ruticilla & 14 & $\mathrm{No}^{\mathrm{b}}$ \\
\hline Gray catbird & Dumetella carolinensis & 14 & $\mathrm{No}^{\mathrm{b}}$ \\
\hline Northern flicker & Colaptes auratus & 12 & Yes \\
\hline Little blue heron & Egretta caerulea & 11 & No \\
\hline Snowy egret & Egretta thula & 10 & No \\
\hline Downy woodpecker & Picoides pubescens & 7 & Yes \\
\hline
\end{tabular}


Table 1. Continued.

\begin{tabular}{|c|c|c|c|}
\hline Common name & Scientific name & Total counted & Mangrove landbird? \\
\hline Roseate spoonbill & Platalea ajaja & 7 & No \\
\hline Fish crow & Corvus ossifragus & 6 & Yes \\
\hline Greater yellowlegs & Tringa melanoleuca & 5 & No \\
\hline Spotted sandpiper & Actitis macularius & 5 & No \\
\hline Yellow-crowned night-heron & Nyctanassa violacea & 5 & No \\
\hline Bald eagle & Haliaeetus leucocephalus & 4 & $\mathrm{No}^{\mathrm{a}}$ \\
\hline Black-and-white warbler & Mniotilta varia & 4 & $\mathrm{No}^{\mathrm{b}}$ \\
\hline Common nighthawk & Chordeiles minor & 4 & $\mathrm{No}^{\mathrm{c}}$ \\
\hline Anhinga & Anhinga anhinga & 3 & No \\
\hline Great white heron & Ardea herodias occidentalis & 3 & No \\
\hline Killdeer & Charadrius vociferus & 3 & No \\
\hline Magnificent frigatebird & Fregata magnificens & 3 & No \\
\hline Purple martin & Progne subis & 3 & No \\
\hline Royal tern & Thalasseus maximus & 3 & No \\
\hline Wilson's plover & Charadrius wilsonia & 3 & No \\
\hline American coot & Fulica americana & 2 & No \\
\hline Black-bellied plover & Pluvialis squatarola & 2 & No \\
\hline Black-crowned night-heron & Nycticorax nycticorax & 2 & No \\
\hline Indigo bunting & Passerina cyanea & 2 & $\mathrm{No}^{b}$ \\
\hline Northern waterthrush & Parkesia noveboracensis & 2 & $\mathrm{No}^{\mathrm{b}}$ \\
\hline Ring-billed gull & Larus delawarensis & 2 & No \\
\hline Reddish egret & Egretta rufescens & 2 & No \\
\hline Barn swallow & Hirundo rustica & 1 & $\mathrm{No}^{\mathrm{b}}$ \\
\hline Belted kingfisher & Megaceryle alcyon & 1 & $\mathrm{No}^{b}$ \\
\hline Black vulture & Coragyps atratus & 1 & No \\
\hline Boat-tailed grackle & Quiscalus major & 1 & Yes \\
\hline Least tern & Sternula antillarum & 1 & No \\
\hline Northern bobwhite & Colinus virginianus & 1 & $\mathrm{No}^{\mathrm{c}}$ \\
\hline Northern parula & Setophaga americana & 1 & $\mathrm{No}^{\mathrm{b}}$ \\
\hline Red-tailed hawk & Buteo jamaicensis & 1 & $\mathrm{No}^{\mathrm{b}}$ \\
\hline Worm-eating warbler & Helmitheros vermivorum & 1 & $\mathrm{No}^{b}$ \\
\hline Willet & Tringa semipalmata & 1 & No \\
\hline American white pelican & Pelecanus erythrorhynchos & 1 & No \\
\hline European starling & Sturnus vulgaris & 1 & No \\
\hline Wood stork & Mycteria americana & 1 & No \\
\hline
\end{tabular}

a These raptors were not included in analyses because most individuals were detected flying over survey points, and so cannot be clearly associated with any particular survey location, and because their wide-ranging nature raises the risk of counting the same individual multiple times at different survey locations.

${ }^{b}$ These landbirds were not included in analyses because they use the mangroves only during the winter or as a stopover site during northward migration.

c These resident landbirds were not included in analyses because their use of the mangroves is likely incidental, based on habitat requirements (e.g., ground-nesting common nighthawks and northern bobwhite are unlikely to be residents in the mangroves.

In an effort to better understand the assemblage of landbirds that breeds in Florida's mangroves, we conducted surveys for breeding birds throughout the mangroves of southern Florida from 2008 to 2011. Our objectives were three-fold: first, to quantify the species composition of Florida's mangrove avifauna; second, to describe the distribution of individual species within the avifauna; and third, to generate baseline estimates of abundance for each species of mangrove landbird. In addressing these objectives, we sought to describe and interpret basic patterns of natural history in a group of understudied birds and 
to produce estimates of abundance that would serve as a snapshot of current conditions against which future monitoring data could be compared. In the Results, we describe general, assemblage-wide patterns of abundance and distribution and then provide detailed accounts for each of the mangrove landbirds.

\section{Methods}

\section{Study area}

We conducted this study in the mangrove forests of Florida (Figure 1). Mangroves are found along both coastlines of Florida as far north as $29^{\circ} \mathrm{N}$ (Odum et al. 1982), to roughly Cedar Key on the Gull coast and to Ponce de Leon inlet on the Atlantic coast (U.S. Fish and Wildlife Service 1999). Scattered patches of shrubby black mangrove occur as far north as Louisiana (Penfound and Hathaway 1938). The structural complexity of stands and size of individual trees diminishes greatly to the north, presumably due to stress associated with low winter air temperatures (Lugo and Patterson-Zucca 1977). Florida's mangroves range in structure from shrublands to open woodlands to tall, closed-canopy forests. Within the study area, shrub, or dwarf, mangroves occurred at inland locations along the freshwater marsh mangrove ecotone and in the Florida Keys. Tall, multicanopied forests occurred most often along the large tidal rivers that flow out of the Everglades, where nutrient levels are high and salinities moderate.

\section{Establishing survey points}

We began the study in 2008 by establishing 87 points at which to conduct bird surveys in Everglades National Park and Biscayne National Park, placing points in locations accessible by foot, kayak, or power boat. Points were located along tidal creeks, hiking trails, and on islands in Florida Bay. Points were separated from one another by $\geq 350 \mathrm{~m}$. We also required that the area within a $150-\mathrm{m}$ radius around each point have $\geq 50 \%$ cover by mangrove vegetation (red mangrove, black mangrove, white mangrove, or buttonwood, alone or as mixed-species assemblages).

In 2009, we added additional survey points using a general randomized tessellation stratified (GRTS) survey design (Theobald et al. 2007). First, we defined the sampling frame using the Florida mangroves shapefile created by the Florida Fish and Wildlife Conservation Commission (available for download at the Florida Geographic Data Library; http://www.fgdl.org). This shapefile was based on land-use and land-cover data from Florida's water-management districts and defined the approximate extent of mangrove vegetation in the state. Within a geographic information system
(GIS), we laid a systematic grid of points throughout the polygons containing mangrove vegetation. Each point in this grid represented a potential survey location. There were 9,654 points in the grid; points were separated from each other by $500 \mathrm{~m}$. We then used S-Draw (T.L. McDonald, Western Ecosystems Technology, Inc., unpublished software; available at http://www.west-inc.com) to generate a GRTS sample of 1,000 potential survey points.

We then applied two decision rules to determine which of the 1,000 potential points would be included in the survey. Beginning with the point drawn first, we determined whether the point was accessible (i.e., along an existing trail, on a navigable creek $<50 \mathrm{~m}$ wide, or on an island that could be surveyed on foot). If the point was accessible, we used it as the midpoint of a route of up to 10 points, each separated by $350 \mathrm{~m}$. A route was defined as a series of points, each directly accessible from at least one other point in the route, that followed a navigable creek or series of navigable creeks or that followed an existing trail. Although strictly speaking this is a cluster design, we treated each point in the route as though it were independent. When the selected point was on an island, additional points were added as space allowed, although many islands contained routes consisting of only the single point selected in the GRTS draw. Once all potential routes were identified, we then determined whether the area within a $150-\mathrm{m}$ radius of each point contained $\geq 50 \%$ mangrove vegetation based on existing land-cover data, inspection of high-resolution digital orthophotos, and physical inspection of the site. Points that did not meet this criterion were discarded. We also discarded two other groups of points for reasons of convenience. First, at the request of the U.S. Fish and Wildlife Service (USFWS), we discarded two survey points that fell on an island that supported a large nesting colony of white-crowned pigeons. Second, we chose not to establish survey points in the area between Broad River and the Ten Thousand Islands because that area is difficult to access and had few opportunities for conducting surveys because of the lack of small tidal creeks.

This process defined our sampling frame, and thus the entity about which we can draw inference. The sampling frame for this study can be described approximately as follows: all areas in southern Florida containing mangrove vegetation that are within $150 \mathrm{~m}$ (the width of our survey area around each point) of a navigable creek $<50 \mathrm{~m}$ wide, islands containing mangrove vegetation on which observers can move on foot, and areas containing mangrove vegetation that are within $150 \mathrm{~m}$ of an existing trail. The process of defining the sampling frame and drawing points resulted in the identification of 159 new survey locations. 


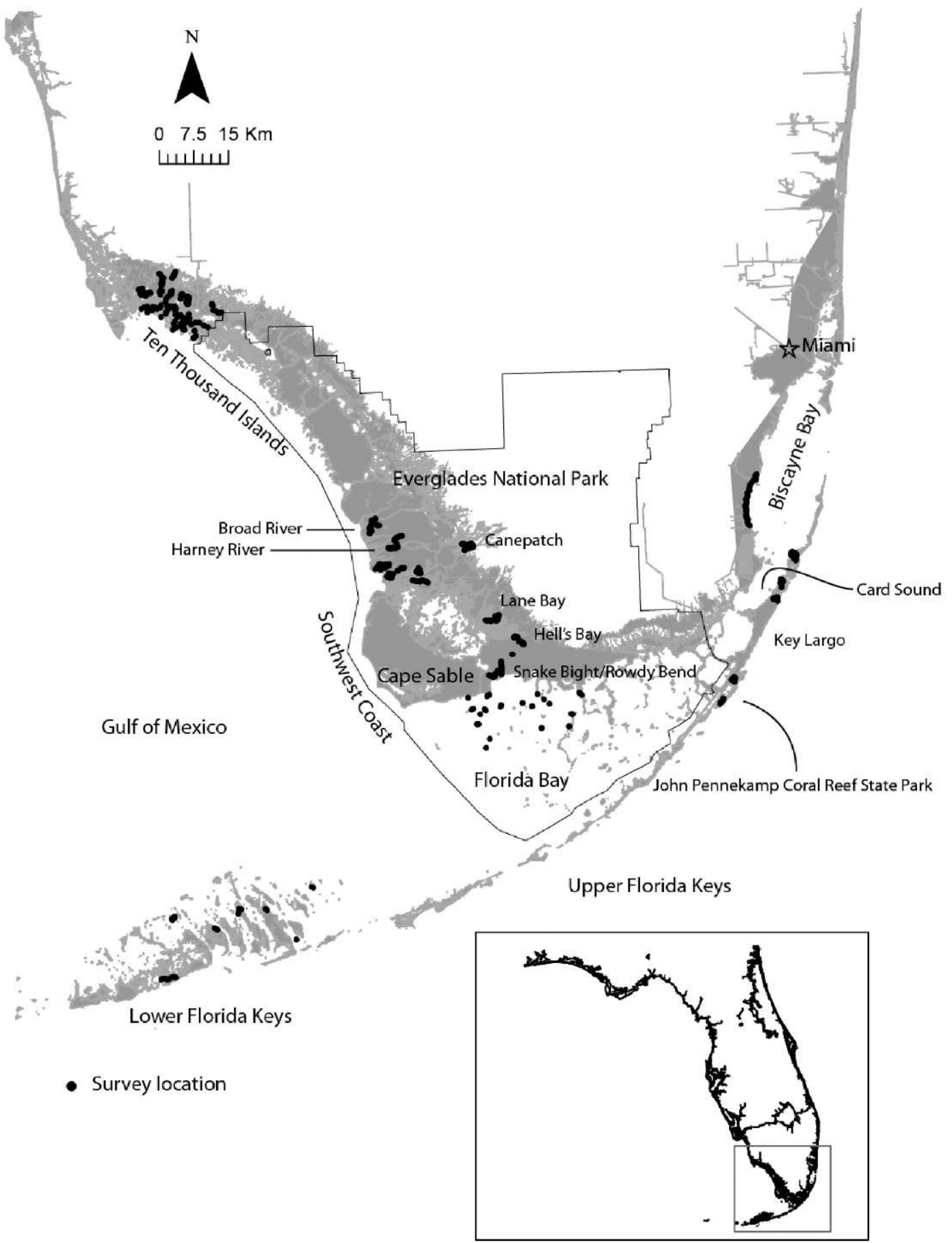

Figure 1. Map of the study area in southern Florida in which surveys were conducted for mangrove landbirds from 2008 to 2011. Shaded gray areas are mangrove vegetation.

In addition, in 2009, we added 108 existing points at Ten Thousand Islands National Wildlife Refuge that had been established as part of a separate, Refuge-based monitoring effort (see Lloyd and Doyle 2011). Although these points were not randomly selected during the GRTS draw, we included them in our sample because they had been surveyed by Ten Thousand Islands National Wildlife Refuge since 1999, which, in the context of mangrove landbirds, amounts to a long-term data 
set. In total, including the original 87 points established systematically, the 159 points established using the GRTS methodology, and the 108 points at Ten Thousand Islands National Wildlife Refuge, we sampled the landbird assemblage at 354 points.

\section{Vegetation cover}

In order to evaluate the extent to which the representation of land-cover types in our survey area was proportional to the representation of landcover types across the mangrove zone of southern Florida (as defined by the Florida mangroves shapefile), we calculated the percent cover by different vegetation types in a 150 -m-radius circle around each survey point using land-cover data produced by the Florida Gap Project (available for download at the Florida Geographic Data I ibrary; http://www.fgdl.org).

\section{Bird surveys}

We surveyed bird populations at each of the 354 points in the study area, although logistical issues precluded us from surveying each point in each year. We surveyed the original 87 points in 2008,347 points in 2009, 325 points in 2010, and 331 points in 2011 . In 2008, surveys were conducted between 1 May and June 4. In 2009, we surveyed points from 25 April until 21 June. In 2010, we surveyed points from 26 April to 28 June. In 2011, we surveyed points from I May to 22 June. The range of dates during which we conducted surveys was based on the experience of other biologists who had conducted bird surveys in mangrove forests in Florida (T. Doyle, USFWS, personal communication) and on our own observations of when passage migrants and wintering species typically left the mangroves and migratory breeders (especially blackwhiskered vireos) returned to the study area and began singing.

Surveys began at sunrise and continued for up to $3 \mathrm{~h}$. Observers were given the discretion to end surveys earlier if they observed that singing rates were declining (e.g., because of elevated air temperatures) or if their perceived ability to detect birds was declining, for example because of increasing wind speeds. Surveys were not conducted in inclement weather (e.g., moderate or heavy rain) or when average wind speed was in excess of $12 \mathrm{~km} / \mathrm{h}$. Surveys consisted of a 10-min count period, during which observers recorded the first detection of each individual within $150 \mathrm{~m}$ of the survey point and assigned that detection to 1 of $101-\mathrm{min}$ intervals. Once an individual was detected, it was not recorded in subsequent intervals.

\section{Statistical analyses}

We generated estimates of abundance in several ways. First, we estimated the mean number of detections per point per species. We used a nonparametric bootstrap routine to estimate the variance and $95 \%$ confidence intervals around estimated means. In this routine, a sample equal in size to the number of points surveyed was drawn with replacement from the observed counts at each survey point. We calculated a mean from this sample, and repeated the process 10,000 times, yielding a distribution of 10,000 sample means. We used the 0.025 and 0.975 percentiles of this distribution as the lower and upper 95\% confidence limits, respectively. Second, we estimated the mean number of detections at points where a species was detected at least once, and estimated the variance and $95 \%$ confidence intervals using the same nonparametric bootstrap routine. Summarizing the average number of detections at points where a species was detected at least once eliminated the distorting effect of averaging across points that either did not include suitable habitat or that were outside of the geographic distribution of a species, and provided a measure of the expected number of individuals present in suitable habitat.

Neither of these methods accounts for the imperfect detectability of individual birds, so we also estimated average abundance and density for each species after correcting for detectability using removal models (Farnsworth et al. 2002) as implemented by the computer program SURVIV (White 1992). We found that we could not generate estimates of detectability $(\hat{p}$, or the probability of detecting an individual that was present during the 10 -min survey period) for species with $<99$ detections, and so we were only able to account for detectability in the 17 most common species. In estimating detectability, we used all detections, both visual and aural. Visual detections accounted for only $8.3 \%$ of all detections. We used Akaike's Information Criterion (AIC) to select between models $M_{c}$, which assumes that individuals of a species differ in their likelihood of detection (i.e., it assumes individual heterogeneity in detectability) and $M$, which assumes all individuals of a species have the same likelihood of detection (Farnsworth et al. 2002). We compared the two models when the data were analyzed in the original 101 -min intervals and when the data were lumped into five 2-min intervals. We considered lumped data because in preliminary analyses we discovered that lumping data into five intervals, especially for species with few detections, sometimes produced a model with a better fit. We used AIC to compare among the four possible models. The model with the lowest AIC was used to estimate $\hat{p}$. We then used $\hat{p}$ to estimate the total number of individuals estimated to have occurred within the area surveyed (i.e., the total number counted as adjusted for $\hat{p}$ ). We then divided the estimated total number of individuals in the 
survey area by the total area surveyed to calculate density. In estimating density, we excluded uninhabitable space such as open water, buildings, or roads from our estimate of the total area surveyed (uninhabitable area was calculated by digitizing high-resolution aerial images of each survey point within a GIS), and so our estimates of density accounted for differences among points in the amount of potentially habitable areas included within the count circle. We also estimated average abundance per point, calculated as the total number of individuals per species divided by the number of surveys conducted. Standard errors for density estimates were calculated using the formula in Farnsworth et al. (2002). Standard errors for the estimates of the total number of individuals and perpoint abundance were calculated using the formula in Nichols et al. (2000).

We multiplied the average of all density estimates for each species (as corrected for detectability and the amount of habitable space within the $150-\mathrm{m}$ count circle) by the total estimated area of mangroves in Florida $(245,256 \mathrm{ha})$, which we calculated from the mangroves shapefile (available for download at the Florida Geographic Data Library; http://www.fgdl.org), to generate estimates of total population size for each species in the mangroves of Florida. We used a nonparametric bootstrap routine, in which we resampled with replacement the density estimates for each species, to estimate 99\% confidence intervals (with limits defined by the 0.01 and 0.99 percentiles) around each estimate of population size.

Abundance estimates could not be presented visually on a point-by-point basis because of the number of points involved and the scale of the area surveyed. Instead, we present information on abundance using a raster grid. Within a GIS, we placed a grid of $300 \mathrm{~m} \times 300 \mathrm{~m}$ cells (approximating the area sampled around each point) across the entire study area. The grid was arranged so that each survey point fell at the center of a cell. We then calculated abundance, averaged across years, for each cell and for each species. We then aggregated adjacent cells to create cells $2.1 \mathrm{~km}$ on each side; it is these larger cells that are displayed in the abundance maps for each species. For each $2.1 \mathrm{~km} \times 2.1 \mathrm{~km}$ cell, we calculated the average abundance of each species by averaging the abundance values for each of the $300 \mathrm{~m} \times 300 \mathrm{~m}$ cells that was aggregated to form the larger cell. Cells without data (i.e., those $300 \mathrm{~m} \times 300 \mathrm{~m}$ cells that had no survey point at their center) were ignored in computing averages during the aggregation process. Raster analyses were conducted using the packages raster (Hijmans and van Etten 2011) and $s p$ (Bivand et al. 2008) within the software $\mathrm{R}(\mathrm{R}$ Development Core Team 2010).

\section{Results}

\section{Vegetation cover}

The representation of land-cover types in the area encompassed by our bird surveys was roughly proportional to the representation of these types across the entirety of Florida's mangrove zone (Table 2; Figure 2). We oversampled red-mangrove forest and undersampled dwarf mangrove, perhaps because the criteria that survey points be accessible by boat or foot favored coastal and riverine forest stands, which were often dominated by red-mangrove and mixed-mangrove forests, and largely ruled out much of the area along the freshwater marsh mangrove ecotone, which were often dominated by dwarl mangroves.

\section{Overall patterns of abundance and distribution}

We detected 80 different bird species during surveys in the mangroves (Table 1). Passeriformes was the most well-represented ordinal taxa, accounting for 29 of the species detected, followed by herons, egrets, and other wading birds in the order Ciconiiformes $(n=13)$. Gulls, terns, and shorebirds (Charadriiformes) accounted for 11 of the species detected. Landbirds accounted for 31 species (Table 1), of which 17 were detected frequently enough to generate estimates of abundance (Table 3). Akaike Information Criterion scores for detectability model $M_{c}$ applied to data lumped into 5 2-min intervals were lowest for all species except mangrove cuckoo and gray kingbird, for which $\operatorname{model} M$, on 52 min intervals and 101 -min intervals, respectively, had the lowest AIC score.

The 18 most common landbirds accounted for $90 \%$ of all detections (Table 3). Although we have no direct evidence of breeding, we assume that all of these species, by virtue of the presence of relatively large numbers of territorial individuals during the breeding season, were breeding in our study area. The remaining 13 landbird species were detected in very low numbers and at very few points $(<6 \%)$, and we are uncertain how they may use mangroves. Some likely breed regularly but in low numbers in mangroves (e.g., eastern towhee in the Hell's Bay area of Everglades National Park), whereas others likely use mangroves incidentally when they abut other habitat types (e.g., blue jay).

Among the 18 landbirds regularly occurring in mangroves, density was strongly and positively correlated with the percentage of points at which a species was detected (Table 3; Figure 3). We broke these species into three groups based on our subjective interpretation of natural breaks in the density and distribution data (Figure 3). The first group consisted of four widespread and abundant species: red-bellied woodpecker, northern cardinal, 
Table 2. Percent cover of different land-cover types within the areas surveyed (survey area) and within the mangrove zone of Florida (statewide). Forest types were distinguished from woodland types based on canopy closure; forests had canopy closure $>60 \%$, whereas woodlands had canopy closure from $25 \%$ to $60 \%$.

\begin{tabular}{lcc}
\hline Land-cover type $^{\text {a }}$ & Survey area & Statewide \\
\hline Mixed-mangrove forest & $37.8 \%$ & $37.6 \%$ \\
\hline Water & $13.9 \%$ & $6.3 \%$ \\
\hline Red-mangrove forest & $11.5 \%$ & $8.0 \%$ \\
\hline Dwarf mangrove & $10.5 \%$ & $15.1 \%$ \\
\hline Buttonwood woodland & $5.3 \%$ & $5.1 \%$ \\
\hline Black-mangrove forest & $3.0 \%$ & $2.6 \%$ \\
\hline Saltwort-glasswort & $2.3 \%$ & $2.3 \%$ \\
\hline Sand cordgrass grassland & $2.1 \%$ & $1.7 \%$ \\
\hline Mixed-mangrove woodland & $1.5 \%$ & $2.2 \%$ \\
\hline Graminoid emergent marsh & $1.2 \%$ & $2.4 \%$ \\
\hline Flooded broad-leaved evergreen shrubland & $1.2 \%$ & $3.8 \%$ \\
\hline Salt marsh & $1.1 \%$ & $0.7 \%$ \\
\hline Tropical hardwood hammock & $0.01 \%$ & $0.01 \%$ \\
\hline a Land-cover definitions are as per the Florida Gap Project (available for download at the Florida Geographic Data Library; http://www. \\
\hline fgdl.org).
\end{tabular}

Florida prairie warbler, and white-eyed vireo. Of these species, only Florida prairie warbler is restricted to mangroves; all of the others are common in a variety of vegetation types throughout much of the eastern United States.

The second group that we identified consisted of four species-great crested flycatcher, pileated woodpecker, American crow, and black-whiskered vireo-that occurred at intermediate densities and that were found at $4070 \%$ of the points surveyed. All of these species were widespread in the study area, but were found in lower numbers than members of the first group.

The third group of species that we identified common yellowthroat, red-shouldered hawk, Cuban yellow warbler, mangrove cuckoo, gray kingbird, Carolina wren, mourning dove, and common grackle - consisted of species either found at low abundance throughout the study area (e.g., mangrove cuckoo and red-shouldered hawk) or that had limited distributions that made them appear relatively uncommon when detections were averaged across all points in the study area (e.g., Cuban yellow warbler and gray kingbird).

In addition, 2 species among the 18 most abundant mangrove landbirds showed anomalous relationships between abundance and distribution (Figure 3). Red-winged blackbirds and whitecrowned pigeons both had limited distributions within the study area yet both species occurred in relatively high densities and had high average counts per point (Figure 3; Table 4). This pattern is due largely to the gregarious nature of both species; when present, both were counted in large numbers. Red-winged blackbirds, with their polygynous mating system, tended to be detected in groups when suitable habitat was present (i.c., freshwater marsh adjacent to mangroves), as did white-crowned pigeons, which nest semicolonially and sometimes feed and roost in large flocks.

Estimated total number of adult individuals inhabiting Florida's mangroves during the breeding season varied widely (Table 5). With the exception of prairie warbler, few of the mangrove specialists were especially abundant; their populations were much smaller than those of widespread species such as red-bellied woodpecker or northern cardinal.

\section{Species accounts}

Red-shouldered hawk. Red-shouldered hawks are common residents of open woodland and forest edge throughout the state (Robertson and Woolfenden 1992). The individuals detected in the mangroves belong to the subspecies endemic to southern Florida (Dykstra et al. 2008). Red-shouldered hawks prey on a variety of small animals, including some aquatic species (Dykstra et al. 2008). We detected red-shouldered hawks throughout the mangroves, including on the small islands of Florida Bay, although we detected them only rarely in the Keys (two detections of lone individuals in the lower Keys (delined as the islands from Key West to Big Pine Key) and two individuals in the upper Keys (all islands north of Bahia Honda) on the north end of Key Largo). They showed little evidence of a preference for one mangrove type over another (Figure 4). 


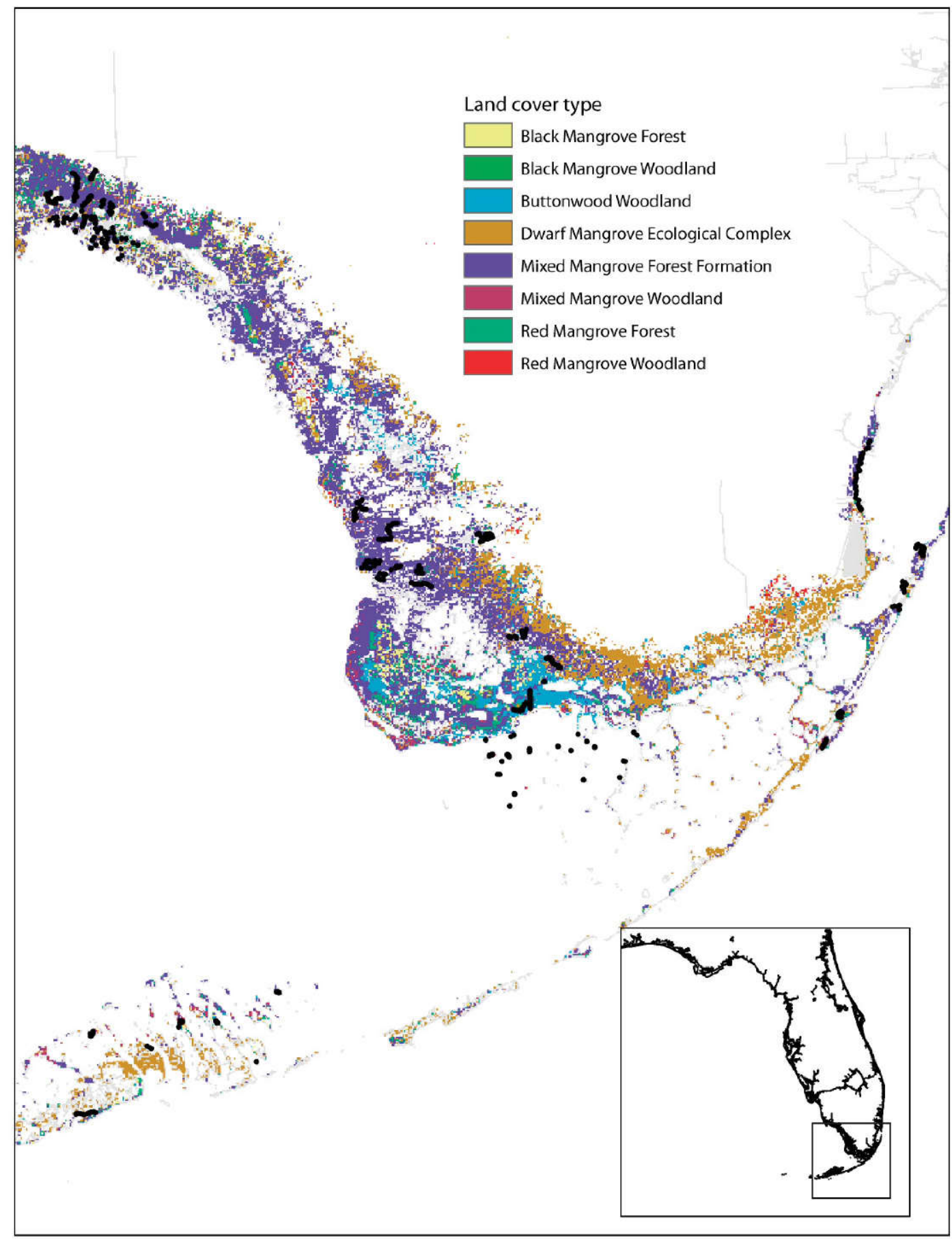

Figure 2. The distribution of study points (black circles) among land-cover types within the study area where we surveyed avifauna in mangroves in southern Florida. Shaded rectangle on inset map shows location of the study area within the state of Florida.

White-crowned pigeon. In Florida, white-crowned pigeons breed primarily on the small mangrove islands of Florida Bay and occasionally on the mainline Florida Keys. They forage and roost in hardwood forests on the lower peninsula and mainline Keys (Stevenson and Anderson 1994; Bancroft and Bowman 2001). Although some birds are found in Florida year-round, most individuals appear to winter in Cuba and the Bahamas, leaving the breeding range by October and returning in 
Table 3. Probability of bird detection $(\hat{p})$; average number counted per survey; average density (no. birds/ha), corrected for detectability; and percent of points present during point count surveys conducted from 2008 to 2011 at 354 locations in mangroves of Florida. Separate estimates of average count, average density, and percent of points present are given for the Keys and Florida Bay for taxa with geographic ranges limited mostly to the southern portion of the study area.

\begin{tabular}{|c|c|c|c|c|}
\hline Species & $\hat{p}$ & Average count & Density & $\%$ present \\
\hline Red-bellied woodpecker & $0.78(0.03)$ & $1.66(0.04)$ & $0.30(0.010)$ & 96.9 \\
\hline Northern cardinal & $0.80(0.04)$ & $1.36(0.05)$ & $0.23(0.009)$ & 92.4 \\
\hline Prairie warbler & $0.75(0.05)$ & $1.12(0.03)$ & $0.23(0.013)$ & 83.2 \\
\hline White-eyed vireo & $0.89(0.02)$ & $1.05(0.03)$ & $0.19(0.004)$ & 75.1 \\
\hline Red-winged blackbird & $0.83(0.04)$ & $0.72(0.04)$ & $0.11(0.005)$ & 36.1 \\
\hline Great crested flycatcher & $0.69(0.08)$ & $0.54(0.04)$ & $0.11(0.010)$ & 68.6 \\
\hline American crow & $0.67(0.11)$ & $0.44(0.03)$ & $0.05(0.007)$ & 44.8 \\
\hline Pileated woodpecker & $0.75(0.05)$ & $0.39(0.02)$ & $0.04(0.003)$ & 56.9 \\
\hline Black-whiskered vireo & $0.66(0.13)$ & $0.31(0.03)$ & $0.07(0.011)$ & 41.2 \\
\hline White-crowned pigeon & $0.72(0.10)$ & $0.33(0.03)$ & $0.06(0.006)$ & 21.3 \\
\hline Keys \& Florida Bay & - & $1.50(0.04)$ & $0.29(0.041)$ & 83.3 \\
\hline Common yellowthroat & $0.71(0.12)$ & $0.07(0.02)$ & $0.01(0.002)$ & 13.2 \\
\hline Red-shouldered hawk & $0.76(0.11)$ & $0.13(0.01)$ & $0.01(0.002)$ & 31.7 \\
\hline Yellow warbler & $0.69(0.17)$ & $0.10(0.01)$ & $0.02(0.003)$ & 11.2 \\
\hline Keys \& Florida Bay & - & $0.59(0.04)$ & $0.08(0.021)$ & 38.8 \\
\hline Mangrove cuckoo & $0.58(0.14)$ & $0.09(0.01)$ & $0.03(0.005)$ & 24.9 \\
\hline Gray kingbird & $0.73(0.10)$ & $0.15(0.02)$ & $0.03(0.003)$ & 19.1 \\
\hline Keys \& Florida Bay & - & $0.63(0.05)$ & $0.15(0.021)$ & 83.3 \\
\hline Carolina wren & $0.83(0.08)$ & $0.12(0.01)$ & $0.02(0.001)$ & 27.2 \\
\hline Mourning dove & $0.87(0.09)$ & $0.10(0.01)$ & $0.01(0.001)$ & 16.0 \\
\hline Keys \& Florida Bay & - & $0.31(0.05)$ & $0.05(0.001)$ & 44.6 \\
\hline Common grackle & - & $0.06(0.01)$ & - & 14.0 \\
\hline All landbirds combined ${ }^{a}$ & $0.76(0.02)$ & $8.98(0.05)$ & $1.67(0.036)$ & - \\
\hline
\end{tabular}

a Includes the 18 species listed in this table, plus the additional 13 mangrove landbirds with too few detections to estimate density.

April. Breeding is closely tied to the phenology of fruiting among hardwoods, especially poisonwood Melopium loxiferum, and can occur anytime between May and September (Bancroft et al. 2000).

To avoid disturbing nesting pigeons, we eliminated two survey points that fell within known nesting colonies; therefore many of the birds detected during our surveys may have been foraging or roosting. Censoring points within known nesting colonies is likely to yield estimates of density that are biased low, although we suspect that in this case the bias is relatively small. Large colonies in the Keys may support 10-50 pairs at any given time during the breeding season (e.g., Bancroft et al. 2000), and these individuals are spread across the colony, so that only some fraction would be counted during a point-count survey such as ours. Given expected densities of birds in these colonies, and given that we excluded only two points, it seems unlikely that our average count (and thus our estimates of density and abundance) would have substantially shifted had the censored points been included.
The best model of detectability was $M_{c}$ with data in five 2-min intervals $(\mathrm{min} . \triangle \mathrm{AIC}=11.6) . \mathrm{We}$ found white-crowned pigeons at highest densities in the lower Keys and on upper Key Largo, both of which still have undeveloped areas of upland hardwood forest (Figure 5). We found them at lower densities in John Pennekamp Coral Reef State Park, on the mangrove islands of Florida Bay, and along the southern coast of the peninsula along the Snake Bight and Rowdy Bend trails in Everglades National Park (Figure 5). Birds detected along the southern coast of the peninsula were likely using the hardwoods that occur next to the Snake Bight trail that runs adjacent to the old Ingraham Canal. Individual birds were detected at inland sites in Everglades National Park at West Lake and in Hell's Bay. One notable record occurred far inland at the Canepatch area of Everglades National Park, which falls at the ecotone between mangrove and freshwater marsh. This area contains extensive hardwood hammock, and so presumably was being used as a 


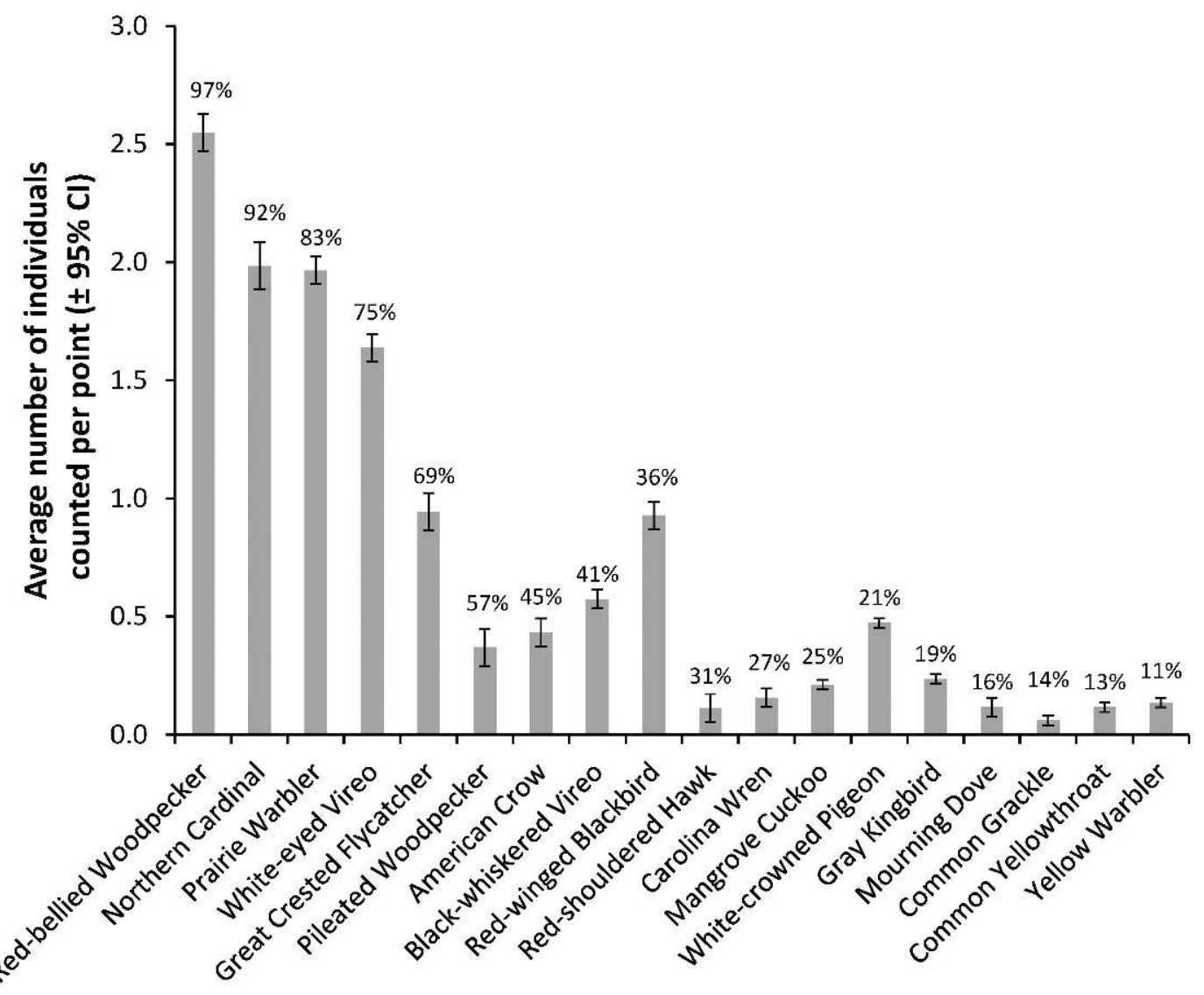

Figure 3. Average number of individual birds counted per point, as corrected for detectability, based on point-count surveys conducted at 354 points in the mangroves of southern Florida from 2008 to 2011 . Numbers above the error bars $(95 \% \mathrm{Cl})$ indicate the percentage of points at which the species was detected at least once.

foraging site by the individual. Stevenson and Anderson (1994) suggested that a breeding population may once have occurred in the Ten Thousand Islands region, but we recorded no detections at any of the 108 points that we surveyed in that region.

Eurasian collared-dove. Furasian collared-dove is a recent arrival to Florida, colonizing the state in the late 1970 s or early 1980 s from populations established earlier in the Bahamas (Woolfenden and Robertson 2006). This species appears to use mangroves incidentally and was detected only in mangroves adjacent to developed areas. Individuals were detected at two points in the narrow fringe of mangroves along Biscayne Bay in Biscayne National Park, at two points on Big Pine Key, at one point on Big Torch Key, at two points in the Card Sound area, and at two points in John Pennekamp Coral Reef State Park.

Mourning dove. Two subspecies of mourning dove occur within the study area: Zenaida macroura carolinensis, the widespread form of the eastern United States, and Z. m. macroura, a West Indian form with a North American distribution apparently limited to the Florida Keys (Aldrich and Duvall 1958). Stevenson and Anderson (1994) reported that this species was rare or absent in the Keys until the 1940 s or $1950 \mathrm{~s}$, but that more recently it had increased in numbers throughout the Keys. Our findings corroborate this suggestion: mourning doves reached their greatest abundance in the Keys, with both numbers and the frequency of occurrence declining to the north (Figure 6; the best model of detectability was $M_{c}$ with data in five 2-min intervals $[\min . \Delta \mathrm{AIC}=17.6])$. We found a large gap in the distribution of this species, beginning on the islands of Florida Bay and continuing inland into Everglades National Park, most of Biscayne National Park, and all the way through the southwestern coast to the Ten Thousand Islands region. In the Ten Thousand Islands region, mourning doves were again found in relatively high densities.

Unlike Eurasian collared-doves, we found mourning doves at points surrounded by extensive mangrove forest. For example, we detected this 
Table 4. Average number of individual birds detected per point for mangrove landbirds with $>100$ detections from 2008 to 2011, excluding points at which the species was never detected. Data were collected in a $150-\mathrm{m}$ radius around 354 points in mangrove vegetation in South Florida.

\begin{tabular}{lll}
\hline Species & $\begin{array}{c}\text { Average no. } \\
\text { detected/point }\end{array}$ & $95 \% \mathbf{C l}$ \\
\hline Red-winged blackbird & 1.94 & $1.78-2.09$ \\
\hline Red-bellied woodpecker & 1.81 & $1.61-2.01$ \\
\hline White-eyed vireo & 1.47 & $1.37-1.60$ \\
\hline Northern cardinal & 1.41 & $1.33-1.49$ \\
\hline Prairie warbler & 1.36 & $1.25-1.46$ \\
\hline Yellow warbler & 1.32 & $0.97-1.67$ \\
\hline White-crowned pigeon & 1.30 & $1.02-1.55$ \\
\hline Great crested flycatcher & 0.83 & $0.76-0.90$ \\
\hline Black-whiskered vireo & 0.83 & $0.72-0.93$ \\
\hline American crow & 0.82 & $0.73-0.91$ \\
\hline Pileated woodpecker & 0.82 & $0.76-0.89$ \\
\hline Gray kingbird & 0.74 & $0.61-0.88$ \\
\hline Common yellowthroat & 0.67 & $0.52-0.82$ \\
\hline Mourning dove & 0.53 & $0.41-0.62$ \\
\hline Carolina wren & 0.50 & $0.43-0.56$ \\
\hline Common grackle & 0.39 & $0.27-0.51$ \\
\hline Mangrove cuckoo & 0.38 & $0.33-0.41$ \\
\hline Red-shouldered hawk & 0.37 & $0.33-0.42$ \\
\hline & & \\
\hline & & \\
\hline
\end{tabular}

species regularly in the Ten Thousand Islands region, which is largely undeveloped and supports large stands of mangrove forest. However, a closer examination of the distribution of mourning doves in this region suggests that they avoided most of the offshore keys, instead using mangrove forests farther inland along tidal rivers (Figure 7). Thus, individuals may be using the mangroves for nesting but travelling farther afield to find open, dry areas suitable for foraging. A similar segregation of nesting and foraging habitat might explain the use of mangrove forests in the Keys, where most patches of mangroves were within a relatively short distance of areas more suitable for a ground-foraging bird.

The split distribution that we observed at higher densities in the south and north of the study area, but absent from the middle-might also reflect the current distribution of the two subspecies that occur in Florida. Data in Aldrich and Duvall (1958) and Stevenson and Anderson (1994) suggest that individuals in the Keys and the Ten Thousand Islands region represent Z. m. macroura and Z.m. carolinensis, respectively. If the Keys population is composed of individuals of Z. m. macroura, then the high densities of individuals in that region may reflect a growing population of this apparently recent colonist (Rob-
Table 5. Estimated total number of adult individuals in southern Florida's mangroves by bird species, identified during surveys conducted from 2008 to 2011. Population estimates were based on density estimates that accounted for individuals present but undetected during surveys. Confidence intervals were generated using a nonparametric bootstrap routine.

\begin{tabular}{|c|c|c|}
\hline Species & Population size & $99 \% \mathrm{Cl}$ \\
\hline Red-bellied woodpecker & 86,048 & $80,043-93,706$ \\
\hline Northern cardinal & 61,047 & $56,204-66,240$ \\
\hline Prairie warbler & 58,348 & $52,647-65,060$ \\
\hline White-eyed vireo & 48,981 & $43,432-54,916$ \\
\hline Red-winged blackbird & 32,489 & $26,107-40,596$ \\
\hline Great crested flycatcher & 29,365 & $25,574-33,331$ \\
\hline Pileated woodpecker & 23,334 & $19,738-26,662$ \\
\hline American crow & 20,468 & $16,335-25,132$ \\
\hline Black-whiskered vireo & 20,061 & $16,018-24,088$ \\
\hline White-crowned pigeon & 15,582 & $10,633-20,844$ \\
\hline Gray kingbird & 8,639 & $5,863-12,022$ \\
\hline Yellow warbler & 8,435 & $4,439-12,934$ \\
\hline Mangrove cuckoo & 6,446 & $4,931-8,289$ \\
\hline Carolina wren & 5,813 & $4,421-7,350$ \\
\hline Red-shouldered hawk & 5,662 & $4,431-6,812$ \\
\hline Common yellowthroat & 4,762 & $2,833-6,829$ \\
\hline Mourning dove & 3,757 & $2,430-5,249$ \\
\hline
\end{tabular}

ertson and Kushlan 1974). The absence of individuals on apparently suitable islands in Florida Bay and along the extratidal buttonwood and blackmangrove forests of the southern coast of the Peninsula may then rellect a temporary gap as the Keys population gradually extends its range northward. To the north, the population in the Ten Thousand Islands region may be composed of individuals of carolinensis, perhaps less suited to environmental conditions farther south. However, Aldrich and Duvall (1958) and Bond (1942) reported breeding-season records of individuals of carolinensis from the Bahamas and Dominican Republic, which would argue against any obvious southward barrier to this subspecies, but Schwartz and Klinikowski (1963) argued that most Bahamas records of mourning dove are referable to Z. m. macroura, not z. m. carolinensis.

Common ground-dove. Common ground-dove occurs across southern North America, through Central America, and into northern South America, occupying nearly any open habitat within that range (Bowman 2002). Neither Stevenson and Anderson (1994) nor Robertson and Kushlan (1974) identify mangroves as habitat for this species, although common ground-doves nest in 


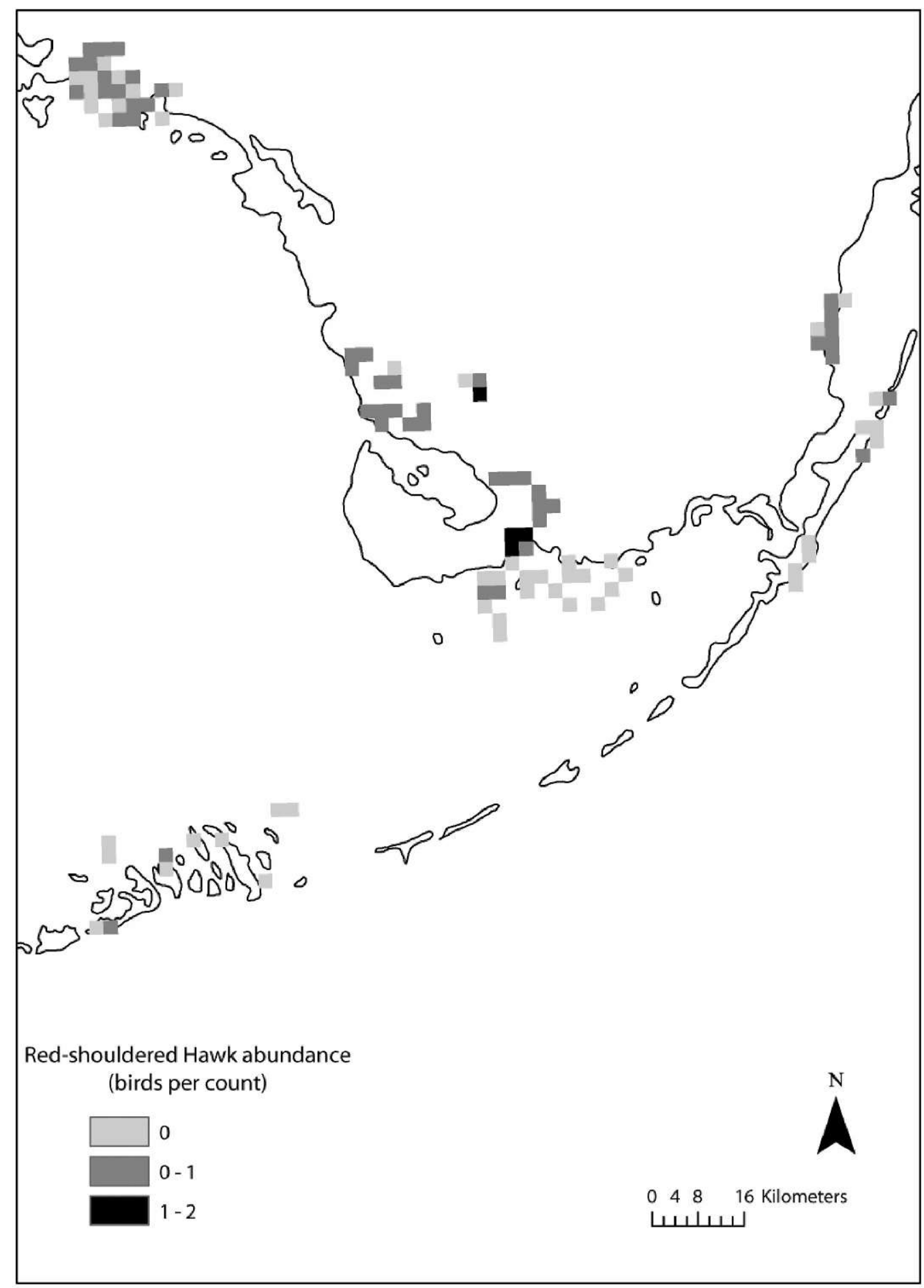

Figure 4. Estimated average abundance of red-shouldered hawk in mangrove vegetation in southern Florida, as recorded in surveys conducted during May-July, 2008 to 2011.

mangroves in other parts of their range (e.g., Costa Rica, Barrantes [1998]; but not in mangroves on Litule Cayman, Diamond [1980]). In Florida, common ground-doves are a permanent resident throughout the state. We found them scattered throughout every region of our study area, from Lower Sugarloaf Key, through the islands of Florida Bay, along the southwestern coast, and into the Ten 


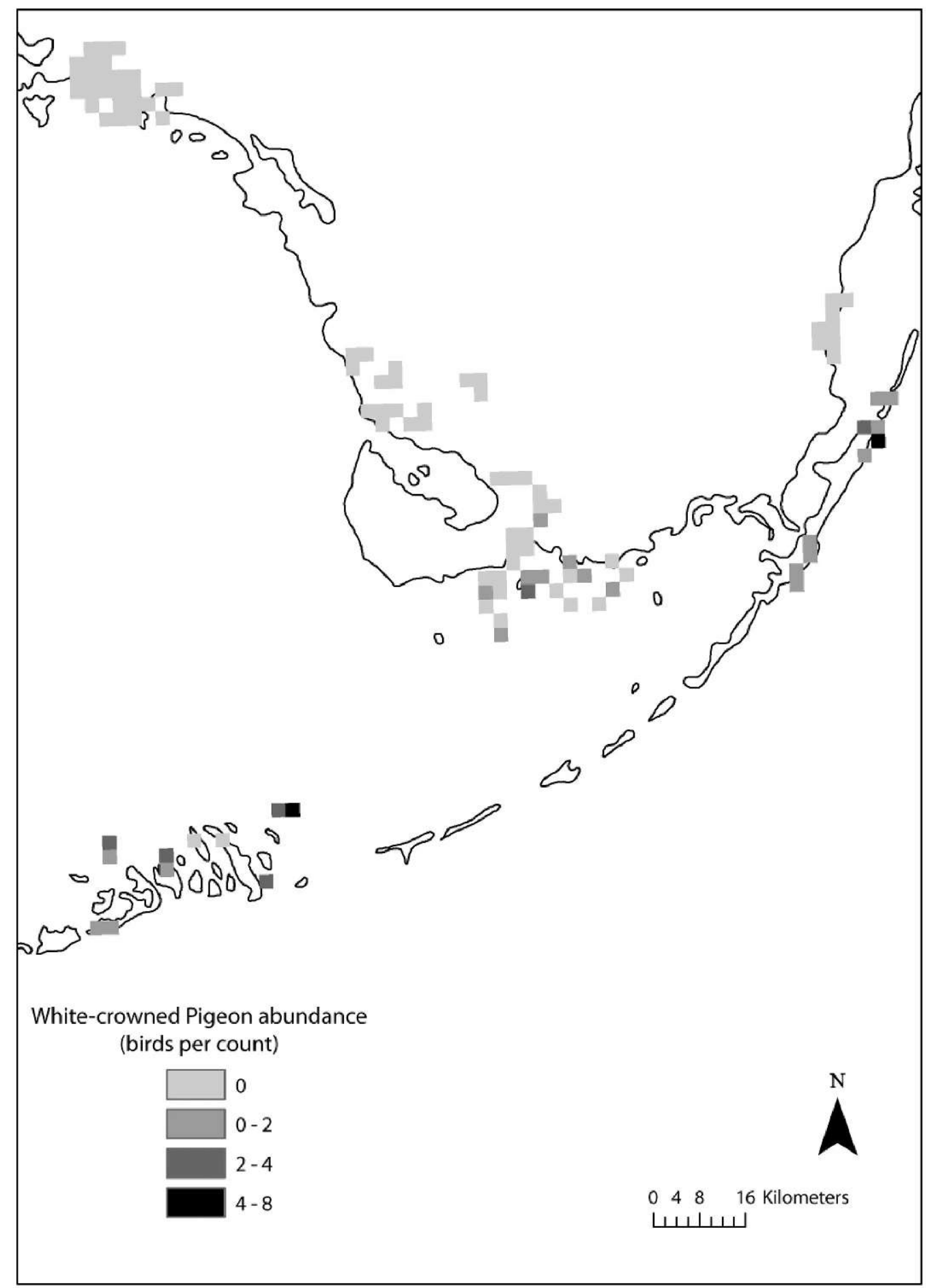

Figure 5. Estimated average abundance of white-crowned pigeon in mangrove vegetation in southern Florida, as recorded in surveys conducted during May-July, 2008 to 2011.

Thousand Islands. Individuals were always detected as pairs or lone individuals, and at only two points one in the fringing forests of Biscayne Bay and one on Lower Sugarloaf Key did we detect individuals in $>1$ y. The lack of consistent detections at any survey point complicates interpretation of our data, as does the extended breeding season of this species (Stevenson and Anderson 1994). 


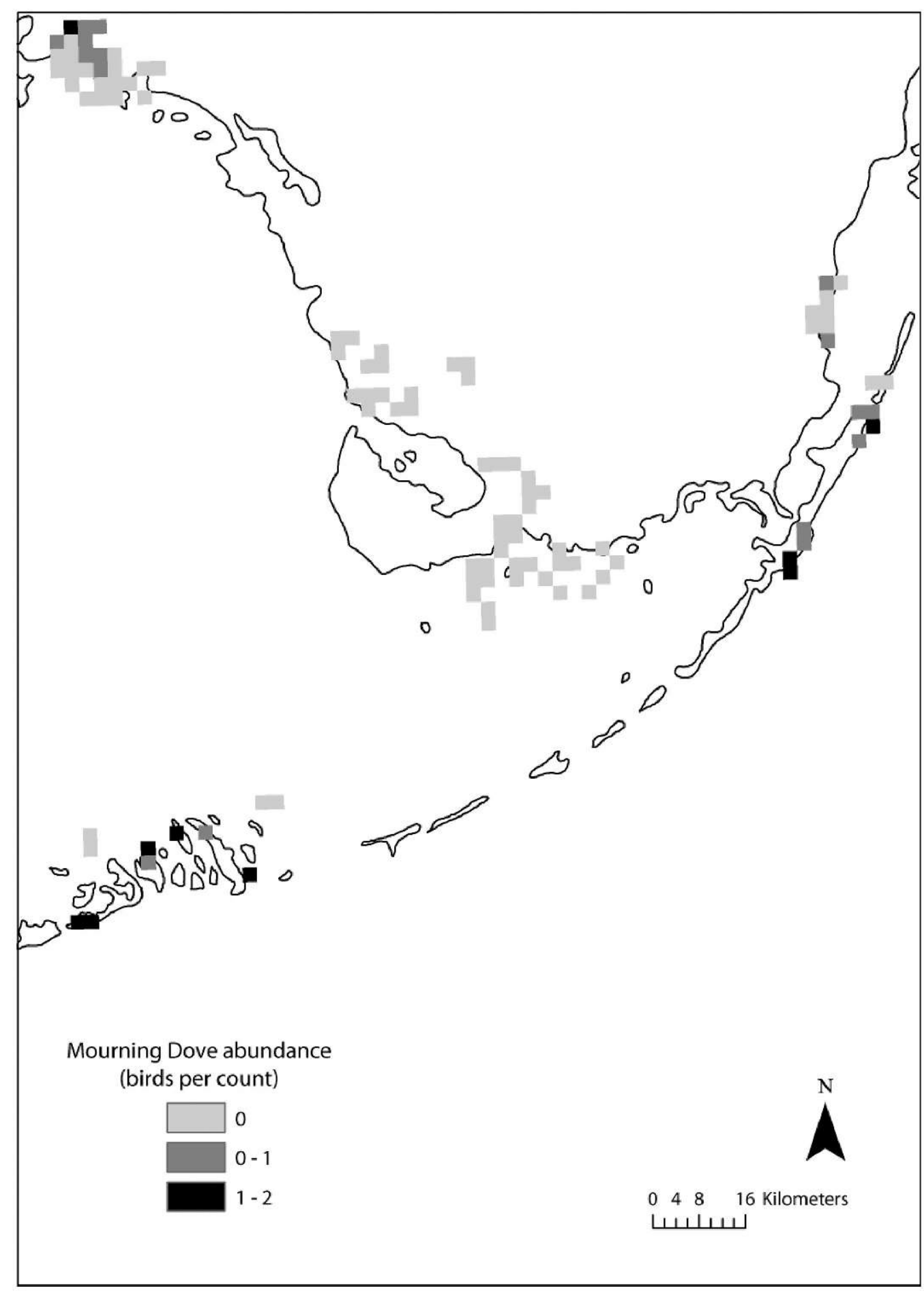

Figure 6. Estimated average abundance of mourning dove in mangrove vegetation in southern Florida, as recorded in surveys conducted during May-July, 2008 to 2011.

rellow-billed cuckoo. Yellow-billed cuckoos breed throughout Florida, including in forest edges in the Keys (Stevenson and Anderson 1994). We recorded no detections of this species until 2011, when we detected 29 individuals at 19 different survey points, clustered in the Keys and the southwestern coast of Everglades National Park. Detections were noted only in late May and June of 2011. Given the 


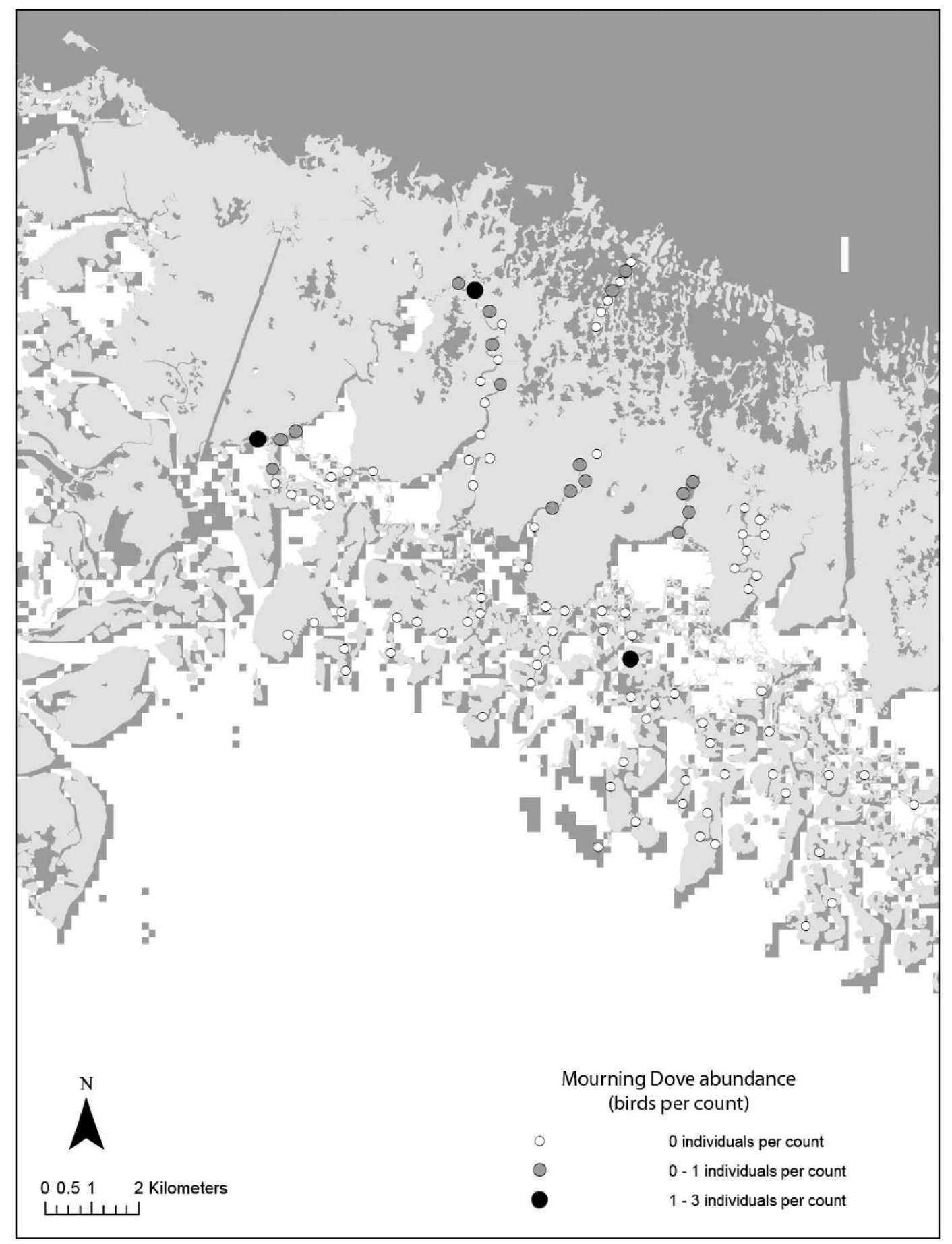

Figure 7. Estimated abundance of mourning dove at survey points in mangrove vegetation in the Ten Thousand islands region of southern Florida, as recorded in surveys conducted during May-July, 2008 to 2011.

apparently extended migration period of this species (Stevenson and Anderson 1994), coupled with the lack of any previous records during our surveys, we suspect that all of the detections of yellow-billed cuckoos reflected late, northward migrants.
Mangrove cuckoo. Perceptions of the status of this breeding species has changed substantially since Scout (1888) wrote of two races, Coccyzus minor maynardi and C. m. minor, inhabiting southern Florida. Following Banks and Hole (1991), this 
species is now considered variable but monotypic pending more detailed taxonomic study. Howell (1932) presented no evidence that mangrove cuckoos were resident in the state during winter, but Robertson and Woolfenden (1992) and Stevenson and Anderson (1994) both argued that the species was a permanent resident based on increasing numbers of winter sightings beginning in the mid1950s. Robertson and Kushlan (1974), Robertson and Woolfenden (1992), and Woolfenden and Robertson (2006) further suggested that this species had expanded its range in recent years, especially into interior locations of the southern peninsula.

Mangrove cuckoos use a variety of forested habitats throughout their range (Hughes 1997), but in Florida rely primarily on mangroves, although individuals may also be found in tropical hammocks during the breeding season (McNair 1991; Karim 2007). We detected mangrove cuckoos throughout the study area, with the exception of the islands of Florida Bay, the dry buttonwood forests of the southern coast of the peninsula, and the interior mangrove shrublands of Everglades National Park (e.g., Hell's Bay). This species was never detected in great numbers, with the highest densities occurring in the Ten Thousand Islands region and on the northern end of Key Largo near Card Sound (Figure 8; the best model of detectability was $M$ with data in five 2 -min intervals $[$ min. $\triangle \mathrm{AIC}=$ 17.6]). We found intermediate densities of mangrove cuckoos in the lower Keys; in the tall, riverine forests along the southwestern coast; and along the edge of Biscayne Bay (Figure 8). Biscayne Bay appears to support a relatively robust population. Although densities were not especially high, we detected at least one Mangrove Cuckoo at 19 of the 25 points surveyed in those forests. Outside of the Ten Thousand Islands region, the only other locations with consistent detections of mangrove cuckoos were along Broad River (detections at 7 of 11 survey points) and Harney River (6 of 15 survey points yielded mangrove cuckoos).

Point-count surveys, including ours, probably underestimate the distribution of mangrove cuckoo. Although its call is loud and unmistakable, mangrove cuckoos vocalize infrequently. They rarely fly when foraging, preferring instead to walk or hop from branch to branch. Thus, when not vocalizing, they are difficult to detect because of the density of vegetation and limited sight distances. Correcting for detectability, although critical for generating accurate estimates of density and abundance (Nichols et al. 2009), does not necessarily address the effect of false absences on estimates of distribution. Future efforts to survey mangrove cuckoos might address this problem by considering environmental covariates when modelling detectability. Using survey methods that increase detectability would also prove useful; for example, broadcasting recorded vocalizations of the typical call of this species before a survey produced a nearly 10 -fold increase in the detection rate as compared with passive point-count surveys (Frieze et al. 2012).

Red-bellied woodpecker. Red-bellied woodpecker is widespread in eastern North America and in recent years has expanded its range well northward into southern Canada (Cadman et al. 2007). Within their growing range, red-bellied woodpeckers occupy nearly any forest type that contains suitable nesting sites (Shackelford et al. 2000). Red-bellied woodpeckers were abundant and ubiquitous during the course of our study (Table 3). They were common throughout the study area, and were found in every type of mangrove forest that we surveyed (Figure 9). The best model of detectability was $M_{c}$ with data in five $2-\mathrm{min}$ intervals (min. $\triangle \mathrm{AIC}$ $=39.9)$.

Downy woodpecker. Downy woodpeckers are locally common in interior forests of Florida, but have not been reported from mangroves. This species either maintains a small, isolated breeding population in the mangroves of the southwestern coast of the peninsula, or is an incidental visitor in this same region. We detected seven total individuals (one pair and five singletons) at six points, one of which was along Wood River (Wood River is a tributary that joins Broad River approx. $2 \mathrm{~km}$ from the Gull of Mexico), just south of its junction with Broad River, and the remaining six of which were in the mangroves around Ponce De Leon Bay of Everglades National Park. Two of the detections came in 2009, and the other five were recorded in 2011. Interestingly, tufted titmice Baeolophus bicolor, which commonly co-occur with downy woodpeckers in the inland forests of southern Florida (e.g., Lloyd and Slater 2011), were once reported to occur along Wood River (Robertson and Kushlan 1974; Stevenson and Anderson 1994), although none were detected during our surveys.

Northern flicker. Northern flickers are breeding residents throughout the state, including the Keys (Stevenson and Anderson 1994; Bancroft et al. 1995). In winter, resident birds are augmented by migrants from northerly breeding populations. We detected only a handful of northern flickers, with 9 of the 12 observations occurring in the narrow strip of mangroves that border Biscayne Bay. The mangrove forests along Biscayne Bay are adjacent to several roads and a variety of other vegetation types (e.g., developed areas and agricultural land) that were probably more suitable for this species, which forages primarily on the ground (Wiebe and Moore 2010).

Pileated woodpecker. Pileated woodpeckers are a fairly common resident of Florida and are found in a variety of forest types (Stevenson and Anderson 1994). Robertson and Woolfenden (1992), Stevenson 


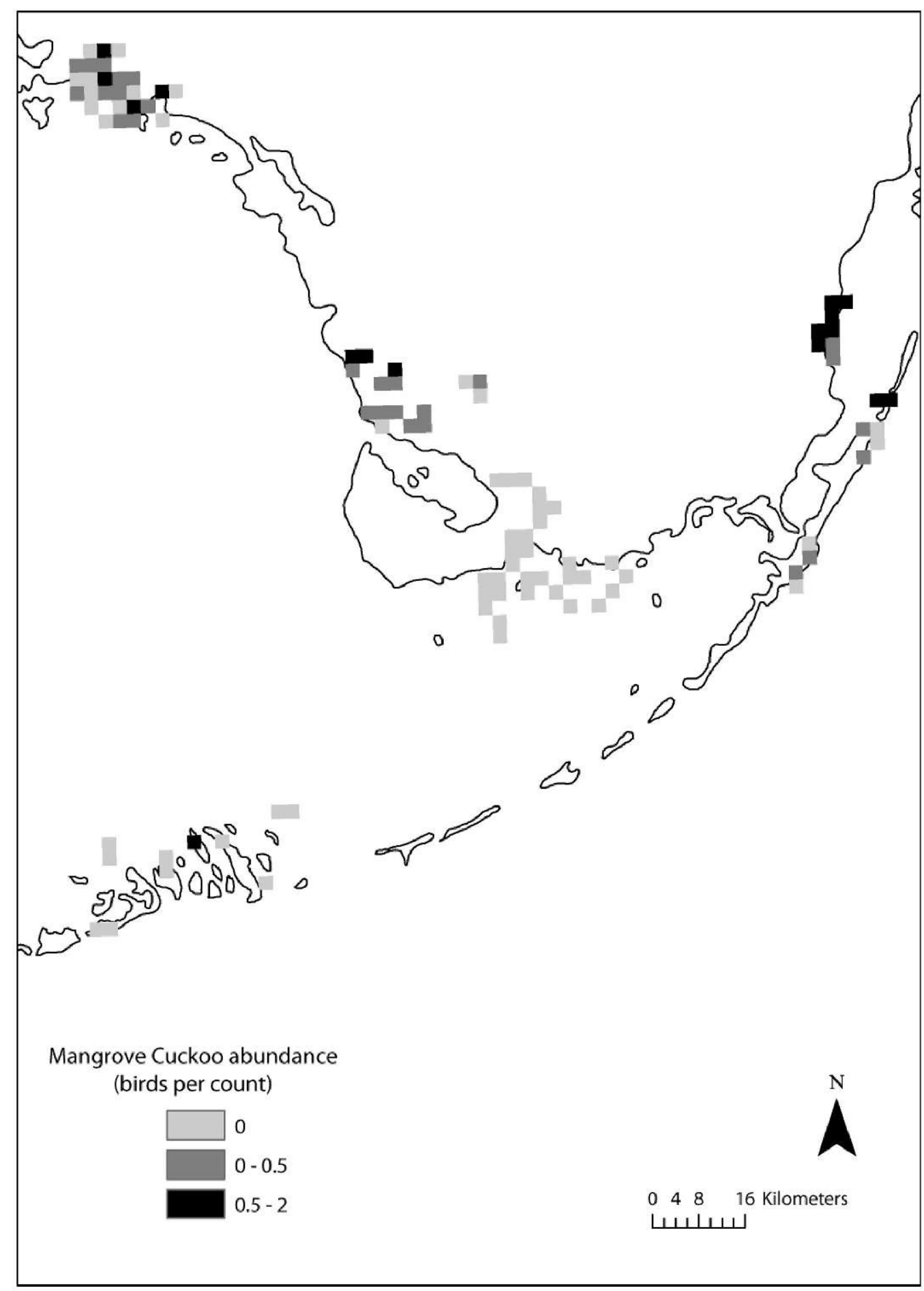

Figure 8. Estimated average abundance of mangrove cuckoo in mangrove vegetation in southern Florida, as recorded in surveys conducted during May-July, 2008 to 2011.

and Anderson (1994), Woolfenden and Robertson (2006), and Cox (2006) all noted a southward decline in the abundance of this species, with relatively few detections in the Keys, especially the lower Keys.
We found Pileated Woodpeckers in moderate densities overall (Table 3). The best model of detectability was $M_{c}$ with data in five 2-min intervals (min. $\triangle \mathrm{AIC}=25.0)$. Although they were found in 


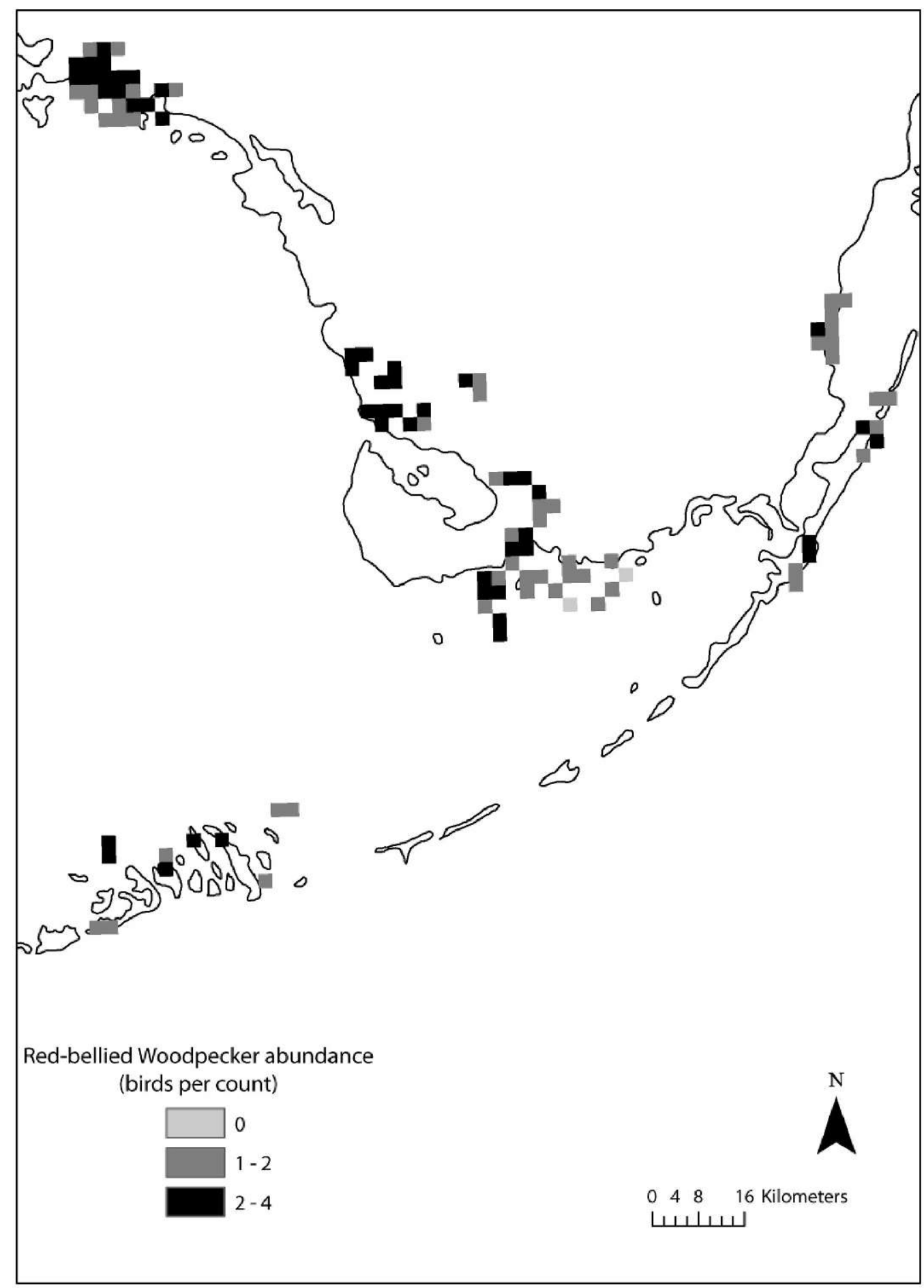

Figure 9. Estimated average abundance of red-bellied woodpecker in mangrove vegetation in southern Florida, as recorded in surveys conducted during May-July, 2008 to 2011.

every region of the study area, including on two of the small islands of Florida Bay (Joe Kemp Key and Murray Key), estimated densities were low outside of two obvious core areas for pileated woodpeckers: the
Ten Thousands Islands region and the riverine forests of the southwestern coast (Figure 10). We detected single individuals or pairs occasionally throughout the Keys as far south as Big Torch 


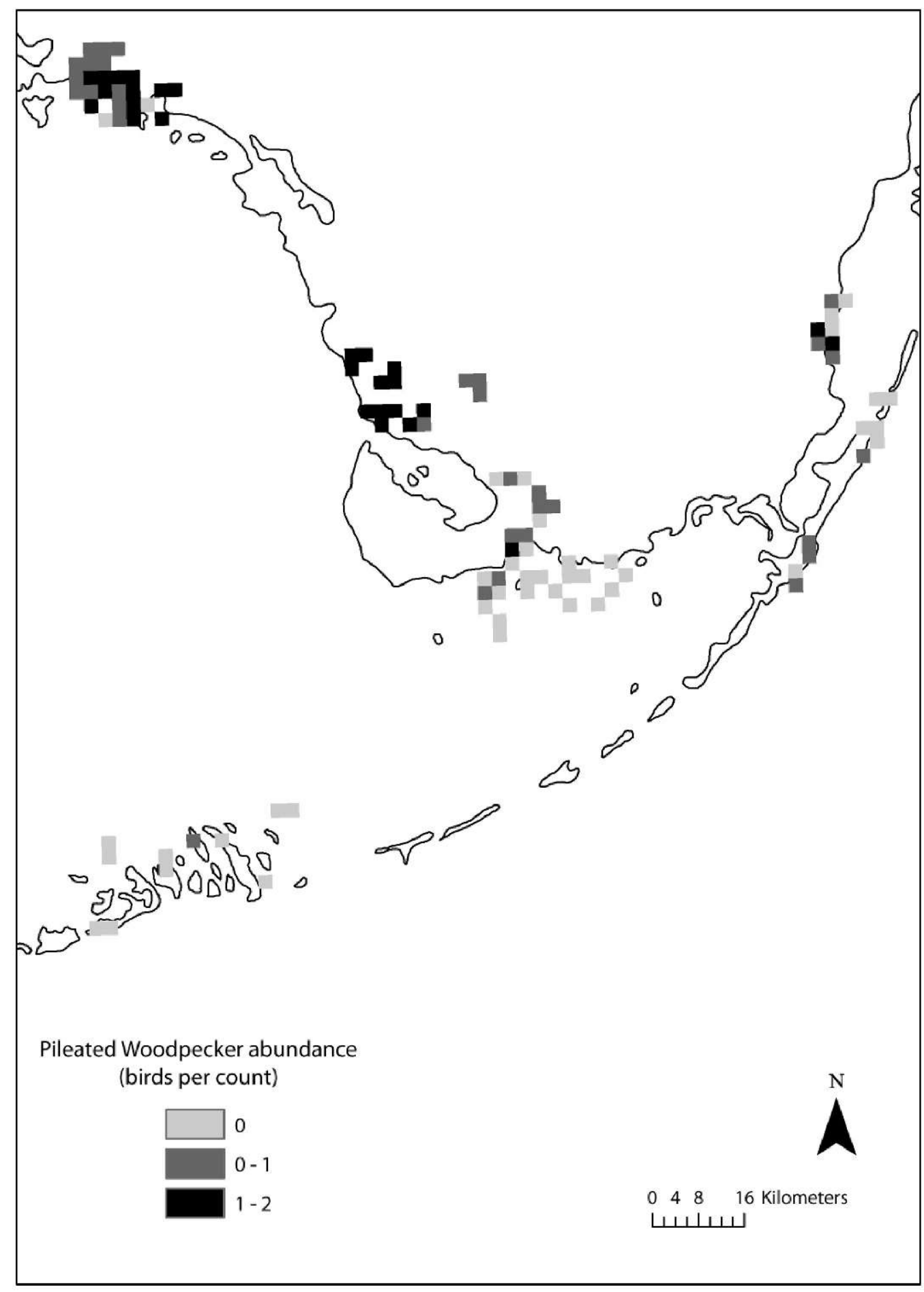

Figure 10. Estimated average abundance of pileated woodpecker in mangrove vegetation in southern Florida, as recorded in surveys conducted during May-July, 2008 to 2011.

Key. Changes in the prevalence of large trees and abundance of snags likely explain the pattern of distribution of pileated woodpeckers in the mangroves. Mangrove forests in the Ten Thousand
Island region and along the large rivers of the southwestern coast contained many tall, largediameter trees and snags and thus probably allowed for a greater density of nesting pairs. Farther south, 
especially in the Keys, we noted fewer trees large enough to support nesting cavities for this species.

Great crested flycatcher. Great crested flycatchers breed throughout the state, although rarely in the Keys, and winter in the southern portion of the state (Robertson and Woolfenden 1992). Nests are built in cavities; according to Stevenson and Anderson (1994:425), "almost any cavity or any height will serve." Great crested flycatchers are not especially sensitive to fragmentation of woodlands (Bancroft et al. 1995), and indeed may benefit from the foraging habitat found around forest edges.

Great crested flycatchers were widespread and found at intermediate densities through much of the study area (Table 3). The best model of detectability was $M_{c}$ with data in five 2-min intervals ( $\mathrm{min}$. $\triangle \mathrm{AIC}$ $=12.1$ ). The distribution of this species was fairly even, with pockets of high density found in all regions except for Biscayne Bay and the upper Keys (Figure 11). Contrary to the situation described by Robertson and Woolfenden (1992) and Stevenson and Anderson (1994), great crested flycatchers were detected regularly and frequently in the lower Keys, especially on Big Torch Key. This may reflect a continuation of the southward advance of this species, first described by Robertson and Kushlan (1974).

The paucity of records of great crested flycatchers in the dense, relatively short forests of the upper Keys and Biscayne Bay may reflect a lack of nesting habitat in these areas. Bancroft et al. (1995) suggested that the distribution of great crested flycatchers in the Keys might be driven by the availability of nest sites. Red-bellied woodpeckers, which are probably the most important excavator of cavities used for nesting by great crested flycatchers, showed a similar pattern of distribution wherein densities were lowest along Biscayne Bay and in the upper Keys (Figure 9).

Gray kingbird. Gray kingbirds are breeding migrants found in coastal areas, and in some inland cities, throughout the state (Stevenson and Anderson 1994; Cox 2006). They have a prolonged migration period, with some autumn departures occurring as late as December, only several months before the earliest northward-moving individuals begin arriving in the state (Stevenson and Anderson 1994). Wintering populations are found throughout the West Indies and into Central and South America (Smith and Jackson 2002).

Overall, gray kingbirds were found at relatively low densities (Table 3), and even within their limited range they never occurred in great numbers. The best model of detectability was $M$ with data in ten 1-min intervals. Model $M_{c}$ with data in ten 1-min intervals was also supported by the data $(\triangle \mathrm{AIG}=$ 1.4), but both models produced similar estimates of detectability $(0.73$ and 0.70 , respectively). Neither of the models evaluated on data split into 2-min intervals were supported (both $\triangle \mathrm{AIC}>150$ ). Although small numbers of gray kingbirds breed much farther north, in our study area gray kingbirds were largely restricted to the Keys and the islands of Florida Bay (Figure 12). The two detections at inland points, both at Lane Bay in Everglades National Park, were of a pair and an individual seen on the same day in mid-May 2009, and may have been migrating individuals. Gray kingbirds like great crested flycatchers and red-bellied woodpeckers - were absent from Biscayne Bay despite occurring in high densities nearby on the north end of Key Largo. The reason that the fringing forests along Biscayne Bay are avoided by gray kingbirds is unclear, but is presumably related to forest structure; given that this species nests in city parking lots in nearby Homestead, it is unlikely that the lack of records along Biscayne Bay reflects the extent of humanrelated disturbance in these forests. Gray kingbirds were also absent from the tall, riverine forests along the southwestern coast and in the Ten Thousand Islands region.

White-eyed vireo. Two weakly differentiated subspecies of white-eyed vireo-Vireo griseus griseus across central and northern Florida and $V . g$. maynardi in the Keys and southern coast of the peninsula breed in Florida, and a third may winter in or migrate through the state ( $V . g$. noveboracensis; Stevenson and Anderson 1994). White-eyed vireos nest in a variety of vegetation types, with the common thread being the presence of a dense understory of shrubs (Hopp et al. 1995). Along the coast of Florida, white-eyed vireos are associated with stands of red mangrove, which presumably share structural characteristics with the shrubby woodlands that this species occupied inland and farther north (Stevenson and Anderson 1994).

White-eyed vireos were abundant and widespread in the mangroves (Tables 3 and 4). The best model of detectability was $M_{c}$ with data split into 2-min intervals $(\mathrm{min} . \triangle \mathrm{AIC}=28.3)$. Densities were greatest in the Ten Thousand Islands region, but we also detected large numbers of individuals at inland sites in Everglades National Park, including at Hell's Bay, Lane Bay, and Canepatch (Figure 13). Based on the map in Stevenson and Anderson (1994), individuals in the Ten Thousands Islands region were $V . g$ griseus, whereas individuals farther south in Everglades National Park were V. g. maynardi. Farther south, densities declined substantially, and we detected individuals only sporadically and in small numbers in the lower Keys. Dense, shrubby stands of mangrove are common throughout the Keys, and on the islands of Florida Bay, and so the scarcity of white-eyed vireos in the southern part of the region is somewhat puzzling and not obviously related to the availability of habitat. White-eyed vireos in Florida 


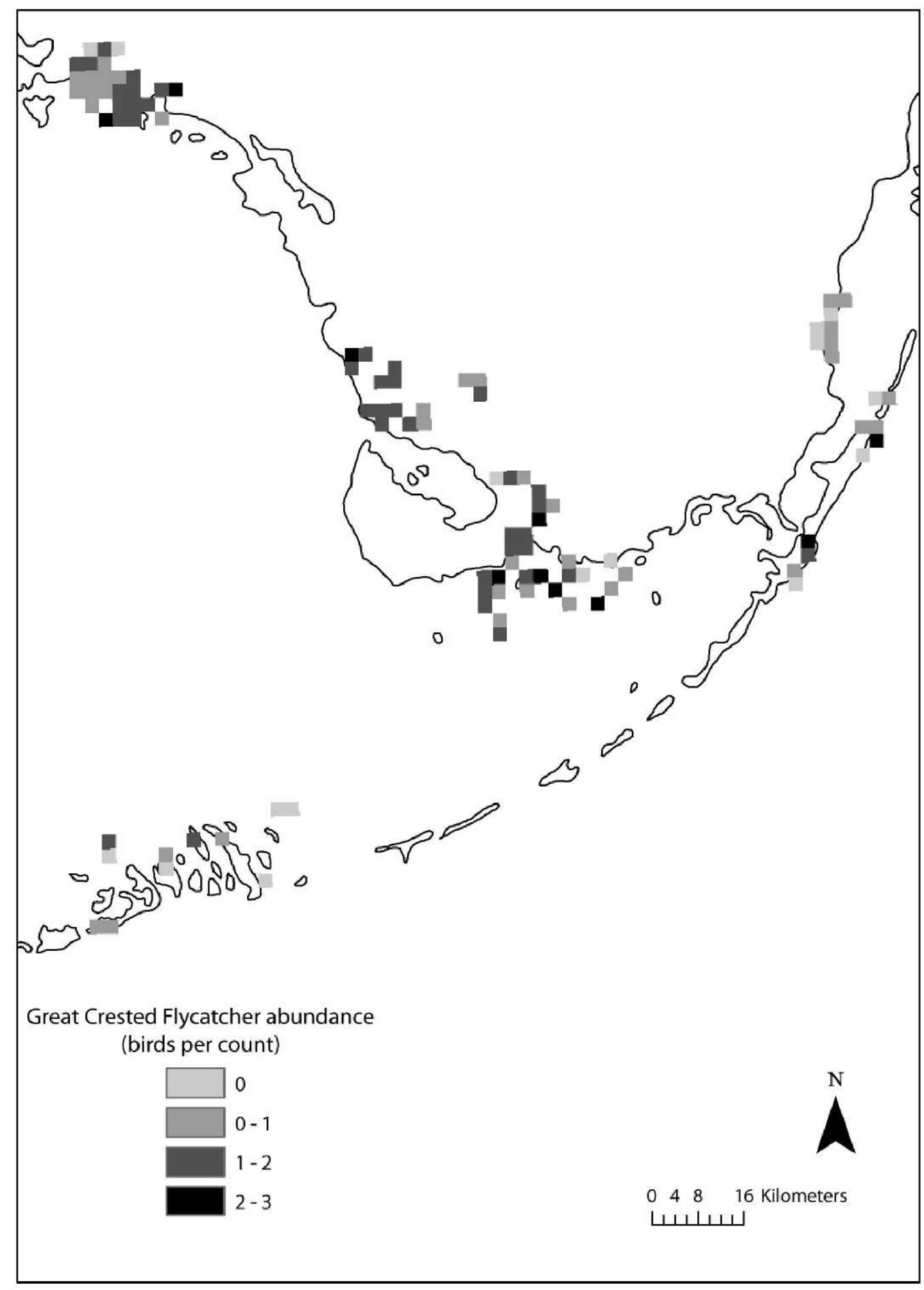

Figure 11. Estimated average abundance of great crested flycatcher in mangrove vegetation in southern Florida, as recorded in surveys conducted during May-July, 2008 to 2011.

Bay and the Keys are at the far southern edge of their breeding range, and so the low densities that we observed may reflect a lack of adaptation to prevailing environmental conditions.
Black-whiskered vireo. Black-whiskered vireos are a West Indian species thought to have colonized Florida in the 1800s (Stevenson and Anderson 1994). Outside of Florida, they are found in a 


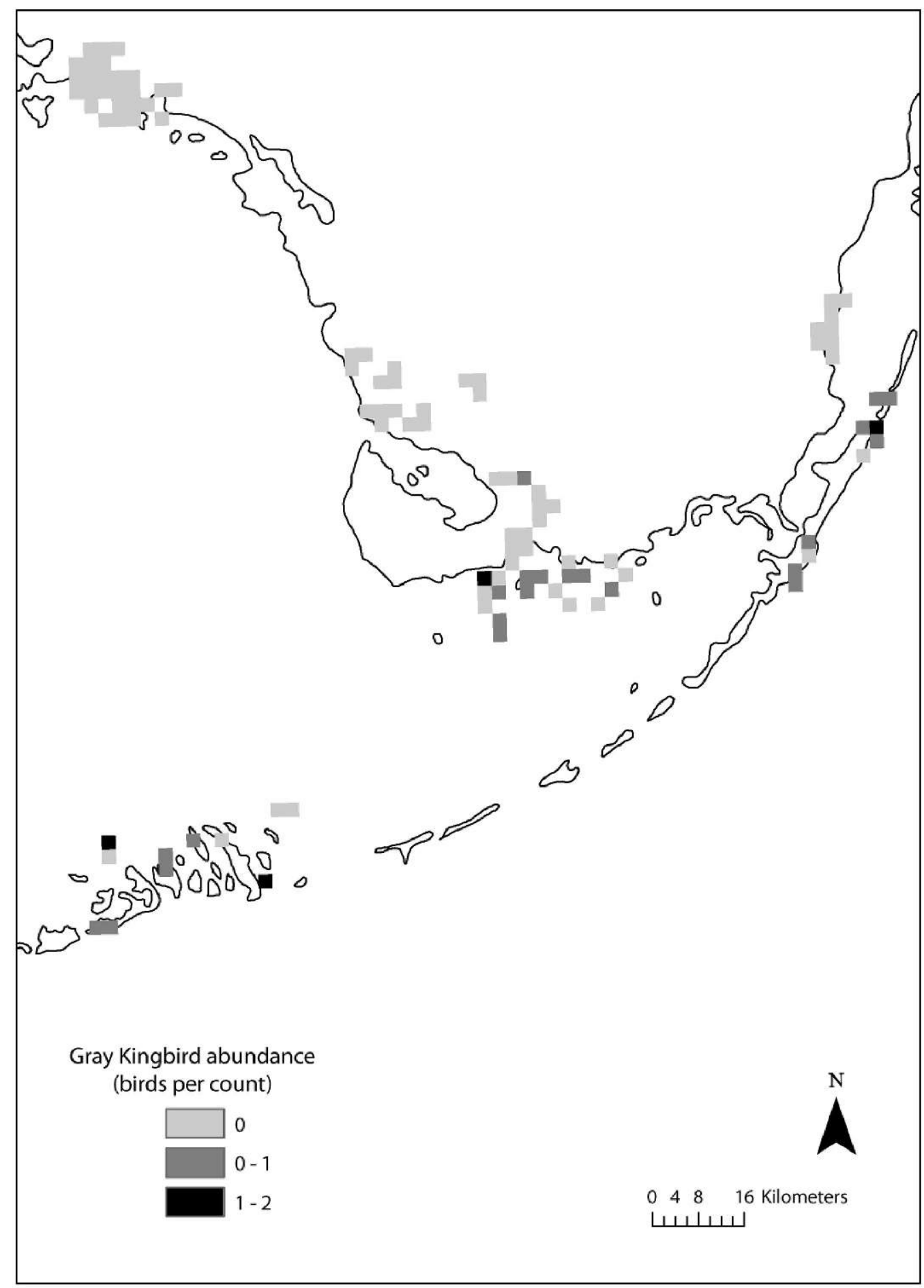

Figure 12. Estimated average abundance of gray kingbird in mangrove vegetation in southern Florida, as recorded in surveys conducted during May-July, 2008 to 2011.

variety of forests; in the state, they are limited to mangrove forests and tropical hammocks (Chace et al. 2002). Most birds leave for their wintering grounds poorly known, but presumed to be northern South America by October, and return in April (Stevenson and Anderson 1994).

Robertson and Woolfenden (1992) and Woolfenden and Robertson (2006) argued for a northward 


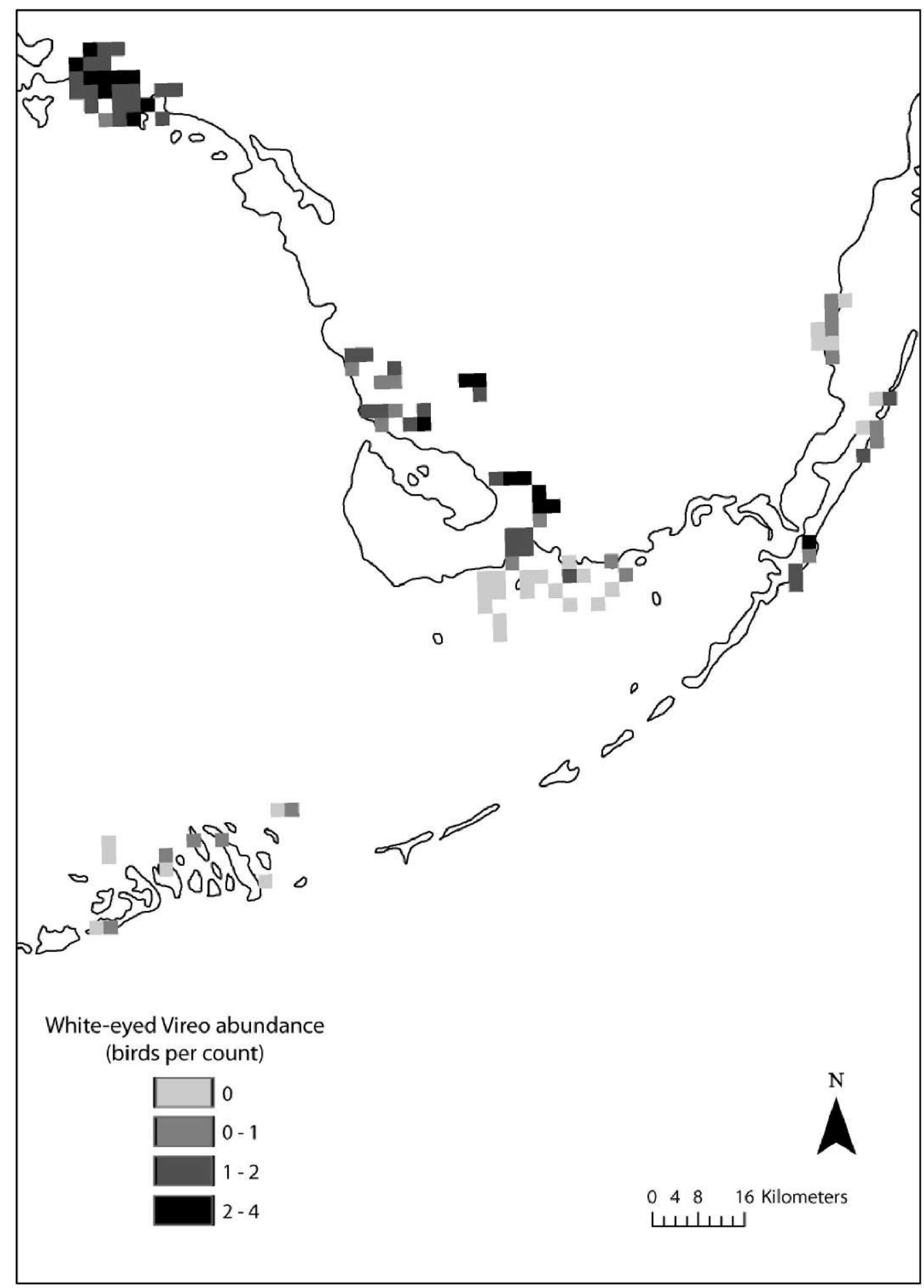

Figure 13. Estimated average abundance of white-eyed vireo in mangrove vegetation in southern Florida, as recorded in surveys conducted during May-July, 2008 to 2011.

and inland range expansion among black-whiskered vireos in recent decades. We found little evidence of extensive use of inland mangroves (Figure 14), but otherwise black-whiskered vireos were evenly distrib- uted in most regions of the study area. With the exception of Florida prairie warbler, black-whiskered vireos were the most abundant of the mangrove specialists (Tables 3 and 4). The only regions with 


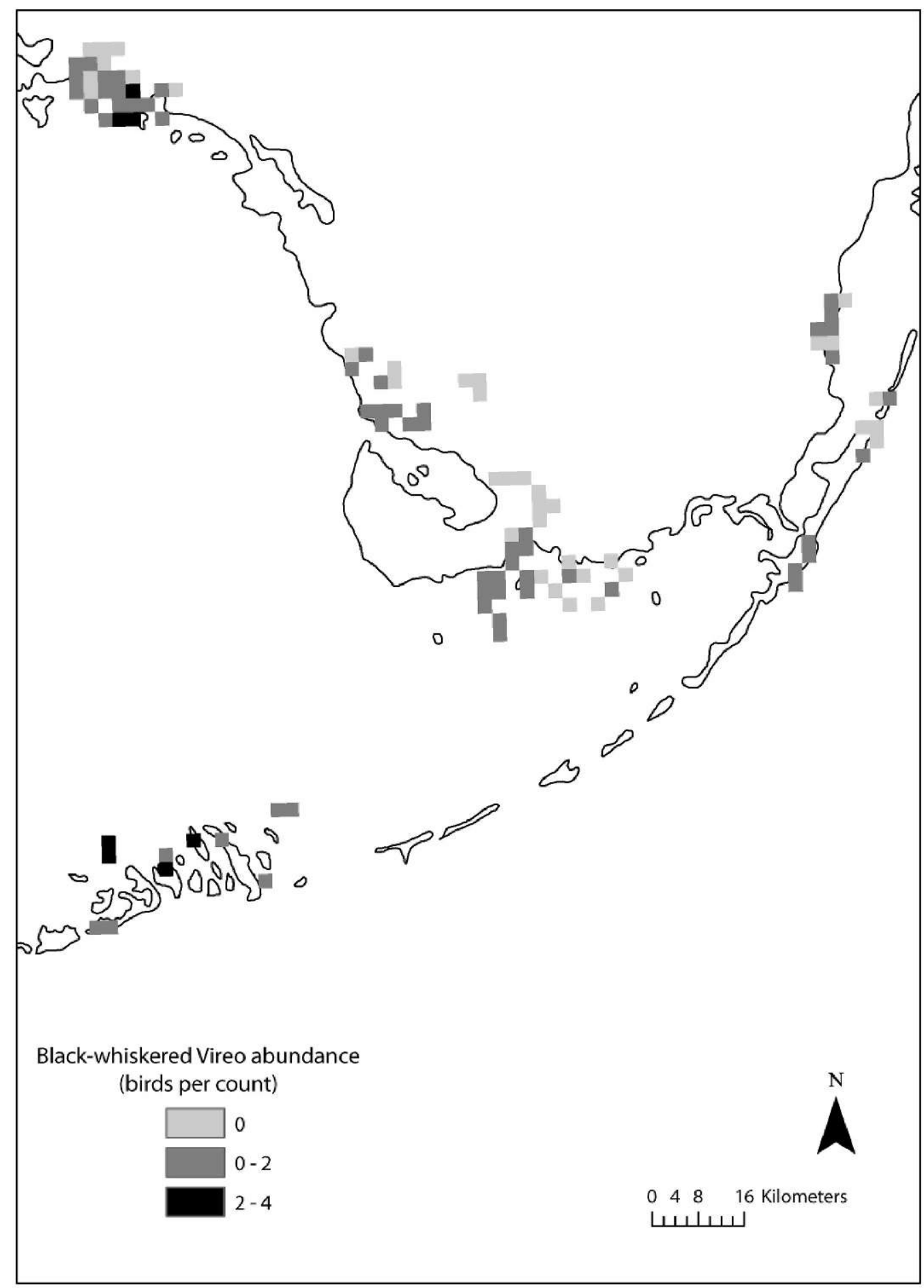

Figure 14. Estimated average abundance of black-whiskered vireo in mangrove vegetation in southern Florida, as recorded in surveys conducted during May-July, 2008 to 2011.

consistently low densities of black-whiskered vireos were Biscayne Bay and the upper Keys. The best model of detectability was $M_{c}$ with data split into 2min intervals ( $\min . \triangle \mathrm{AIC}=19.9$ ).
Blue jay. Robertson (1955) and Robertson and Kushlan (1974) suggested that blue jays in southern Florida had adapted to the loss of their primary habitat pine rocklands by becoming birds of 
forest edge and suburbia. Perhaps accompanying this shift in habitat utilization, blue jays were also reported to have expanded their range in the past century to include parts of the Keys thought to have been previously unoccupied (Robertson and Woolfenden 1992; Woolfenden and Robertson 2006). Not noted as an inhabitant of mangroves, we detected 49 Blue Jays at 19 different survey points-three in the Ten Thousand Islands Region and 16 in Biscayne Bay and the upper Keys (near Card Sound and in John Pennekamp Coral Reef State Park). At five of these points two at Biscayne Bay and three in John Pennekamp Coral Reef State Park-individuals were detected in $\geq 2 \mathrm{y}$. With the exception of the points in the Ten Thousand Islands Region, all of the mangroves in which we detected blue jays had areas of commercial, residential, or agricultural development nearby. Given this, and the mostly irregular nature of the detections, we believe that blue jays are either occasional, incidental visitors to the mangroves or a very uncommon nesting species in mangroves adjacent to suburban development.

American crow. American crows nest during the dry season, typically January through March, and so our surveys fell well outside the breeding season of this species (Stevenson and Anderson 1994). In Florida, American crows generally occur inland, although they also are found around nesting colonies of waterbirds in Florida Bay, where presumably they prey on eggs and young birds (Robertson and Kushlan 1974). Historically, American crows were considered absent from the Keys (Robertson and Kushlan 1974), although more recently they have been described as occasional stragglers to the region (Robertson and Woolfenden 1992; Stevenson and Anderson 1994).

We found American crow to be an abundant member of the mangrove landbird assemblage (Tables 3 and 4), but with a fairly patchy distribution (Table 3; Figure 15). The best model of detectability was $M_{c}$ with data split into 2-min intervals. The same model on data in 1-min intervals was also supported $(\triangle \mathrm{AIC}=1.3)$ and produced a somewhat higher estimate of detectability $(0.76 ; 95 \%$ CI $=$ $0.650 .87)$ than the best model $(0.67 ; 95 \% \mathrm{CI}=$ $0.46-0.88$ ). Model $M$ was not supported in either case (both $\triangle \mathrm{AIC}>25$ ). American crows reached their greatest densities in inland areas along the southern coast, especially along the Snake Bight and Rowdy Bend trails, Hell's Bay, and Lane Bay in Everglades National Park (Figure 15). American crows occur regularly along the main road through Everglades National Park, usually feeding on roadkill, and so some of the elevated densities that we observed in surrounding areas may reflect the subsidies inadvertently provided by the road and the cluster of development in Flamingo. American crows were detected frequently, albeit in lower numbers, in the large forests of the southwestern coast and in the Ten Thousand Islands region. As reported by previous authors, American crows were largely absent from the Keys and Biscayne Bay. We detected lone individuals at five different points, with the southernmost record coming from Lower Sugarloal Key.

Fish crowe. Considered the "city crow" of southern Florida, fish crows are common throughout much of northern and central Florida but are restricted to the coasts and cities of southern Florida (Stevenson and Anderson 1994). Robertson and Woolfenden (1992) reported that fish crows were an irregular visitor to the Keys, but noted the possibility that a small resident population might exist in the lower Keys. We detected only six fish crows (Table 1); three at two different points in John Pennekamp Coral Reef State Park, two at two different points along Biscayne Bay, and one on Clive Key in Florida Bay. Unlike American crows, fish crows breed during the period in which we conducted our surveys, so the records reported here could reflect breeding individuals. However, absent evidence of breeding, we consider fish crows to be an occasional visitor to, and possible rare breeder in, the mangroves of southern Florida.

Carolina wren. Found virtually anywhere in the eastern United States where dense, shrubby vegetation exists (Haggerty and Morton 1995), Carolina wren is common throughout much of Florida (Robertson and Woolfenden 1992; Stevenson and Anderson 1994). Carolina wrens are uncommon in the southern peninsula and the Keys, apparently breeding south of Key Iargo only on rare occasions (Robertson and Woolfenden 1992).

Our lindings portray Carolina wren as a continental species reaching the edge of its range in the mangroves; they were neither widespread nor abundant even where present (Tables 3 and 4), and had a distribution limited primarily to the northern half of the study area (Figure 16). The best model of detectability was $M_{c}$ with data split into 2 -min intervals $(\min . \triangle \mathrm{AIC}=27.2)$. In the Ten Thousand Islands region, where this species reached its greatest density, individuals were absent from the keys and were found only at inland locations along the major tidal rivers (e.g., Blackwater River). We detected four individuals at three points on Key Largo, but found no individuals at any points farther south in the Keys. Carolina wrens seem to be a good example of the uniquely Floridian phenomenon whereby long-established members of a fauna of temperate origin have seized the opportunity to colonize a more recently arrived tropical flora (de Pourtales 1877; Robertson and Kushlan 1974).

Northern mockingbird. We detected only 38 northern mockingbirds (Table 1) at 15 different points. Individuals were detected at six points around Biscayne Bay, seven points around Card Sound, at 


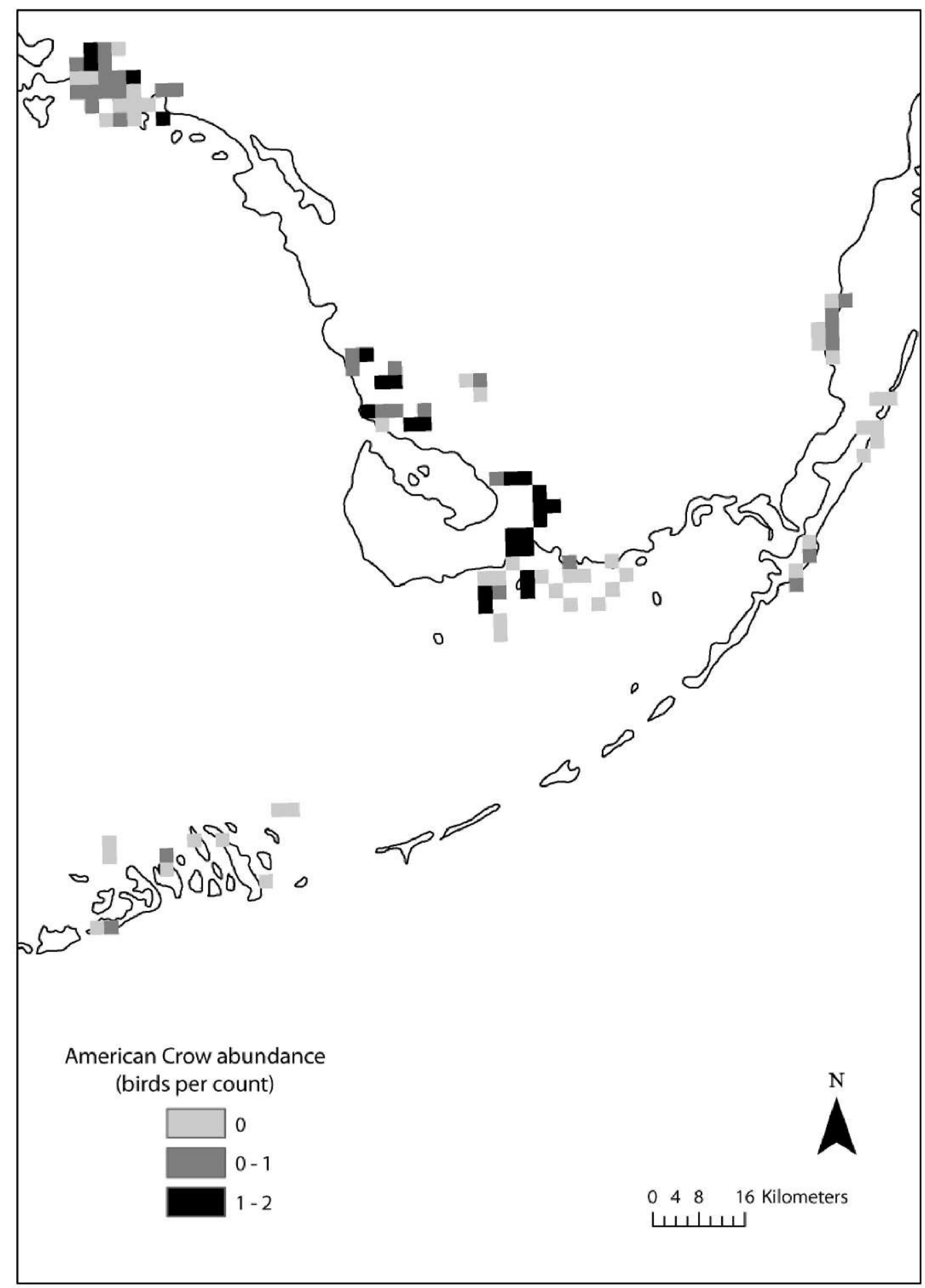

Figure 15. Estimated average abundance of American crow in mangrove vegetation in southern Florida, as recorded in surveys conducted during May-July, 2008 to 2011.

one point on Cudjoe Key, and at one point on Big Pine Key. Similar patterns of distribution were noted for other species associated with settled areas (e.g., Eurasian collared-dove), and so we assume that the presence of northern mockingbirds in the mangroves is largely incidental.

Common yellowthroat. Common yellowthroats breed throughout North America in areas with low, dense 


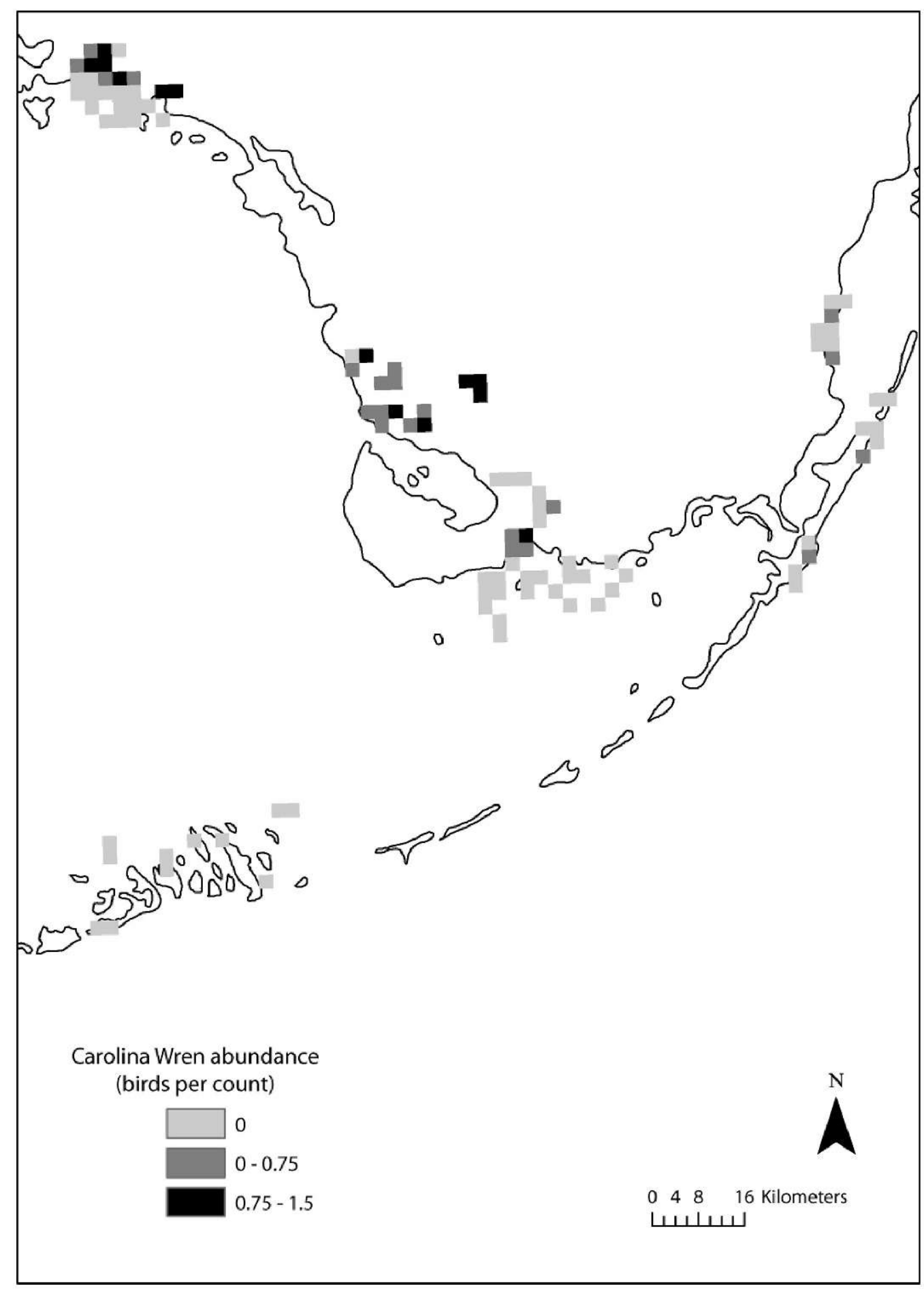

Figure 16. Estimated average abundance of Carolina wren in mangrove vegetation in southern Florida, as recorded in surveys conducted during May-July, 2008 to 2011.

vegetation (Guzy and Ritchison 1999). Resident breeding populations in Florida are joined by winter migrants that begin arriving in September and that linger as late as May (Stevenson and Anderson 1994).
During the winter, common yellowthroats are found throughout the state, including the Keys, but breeding populations are thought to occur no farther south than southern mainland (Stevenson and Anderson 1994). 
Common yellowthroats were neither abundant nor widespread (Table 3). The best model of detectability was $M_{\epsilon}$ with data split into 2-min intervals (min. $\triangle \mathrm{AIC}=5.1$ ). They exhibited a unique pattern of distribution that probably reflects their closer association with habitats other than mangroves (Figure 17). Pockets of high density were noted at several inland locations in Everglades National Park-not surprising given the association that this species has with freshwater marsh and in the lower Keys. Detections of lone individuals were recorded at points scattered throughout all other regions of the study area with the exception of the Ten Thousand Islands area, where none were detected. The presence of common yellowthroats in the lower Keys is somewhat unexpected, given the presumed lack of breeding populations south of the mainland (e.g., Stevenson and Anderson 1994). However, reported migration dates for wintering individuals extend well into May (Stevenson and Anderson 1994), and so we cannot rule out the possibility that the individuals we detected in the Keys were winter migrants. Indeed, most of the detections from the Keys were from late April or early May, and later surveys at these same points yielded no detections. For example, on 30 April 2009, five individuals were counted at a point on Horseshoe Key in Great White Heron National Wildlife Refuge; 5 wk later none were counted at this point. However, another point on Horseshoe Key yielded two individuals on 30 April 2009 and one individual on 26 May 2009. Overall, however, common yellowthroats appear to be only an occasional and opportunistic inhabitant of the mangroves, with a distribution limited largely to mangroves found near inland marshes.

Yellow warbler. Cuban yellow warblers, presumably colonists from either the Bahamas or Cuba, were first discovered in the state when a pair was found nesting in 1941 in Great White Heron National Wildlife Refuge (Greene 1942). At least in Florida, they nest exclusively in mangroves (Stevenson and Anderson 1994; Prather and Cruz 1995). Since their discovery, yellow warblers have spread up the Keys and northward through Florida Bay. According to unpublished sources cited by Robertson and Woolfenden (1992) and Stevenson and Anderson (1994), the breeding range extends into Collier County on the Gull side and to the north end of Biscayne Bay on the Atlantic side of the peninsula. However, we found no evidence that Cuban yellow warblers have extended their range to include the mainland.

The best model of detectability was $M$ with data split into 2-min intervals ( $\min . \Delta \mathrm{AIC}=20.8$ ). Because of their limited distribution within the study area, overall density of Cuban yellow warblers was relatively low (Table 3 ). Within the
Keys and the islands of Florida Bay, however, we found them at much higher densities (Table 3). Indeed, when present, they were one of the most abundant species detected (Table 4). Cuban yellow warblers reached their greatest densities on the small islands of Florida Bay (Figure 18). We detected this species on every surveyed island in Florida Bay with the exception of Big Key, which was surveyed twice in 2011. We also found Cuban yellow warblers at high density at some points in the lower Keys, although they were also absent from many points on the mainline keys, including Cudjoe Key and Big Torch Key (Figure 18). Farther north, we found them at low density in the short red mangrove forests at John Pennekamp Coral Reel State Park and around Card Sound. We recorded only one individual on the mainland, a singing male detected during a single survey along the Snake Bight Trail in Everglades National Park in 2009. Yellow warblers were not detected in Biscayne Bay, the southwestern coast of Everglades National Park, and the Ten Thousand Islands region. Individuals probably wander north of Florida Bay on occasion, but we found no evidence that this species has expanded its regular breeding range to the extent suggested by Robertson and Woolfenden (1992) or Stevenson and Anderson (1994). Based on our data, Cuban yellow warblers are limited primarily, if not exclusively, to the Keys and to the islands of Florida Bay; records of breeding individuals farther northward would be of note and should be carefully examined to rule out the possibility that individuals are migrants belonging to one of the more northerly subspecies, which are uncommon spring migrants (Stevenson 1957; Stevenson and Anderson 1994).

Prairie warbler. The endemic subspecies of prairie warbler that inhabits Florida's mangrove was first described by Howell (1930). Believed to have diverged in the late Pleistocene (approx. 70,000 y ago; Buerkle [1999]) from a common ancestor shared with the nominate subspecies, Setophaga discolor discolor, Florida prairie warblers differ from their northern cousins both morphologically-they are larger and have longer patches of white on the outermost three retrices (Buerkle 2000)-and behaviorally, in that they are nonmigratory. The recorded range of Florida prairie warbler extends farther north than any of the other mangrove specialists, from Pasco County on the Gulf side to Volusia County on the Allantic coast (Robertson and Woolfenden 1992; Stevenson and Anderson 1994). Nesting occurs primarily, but perhaps not exclusively, in coastal mangrove forests (Stevenson and Anderson 1994; Prather and Cruz 1995).

Florida prairie warblers were by far the most common and widespread mangrove specialist in our 


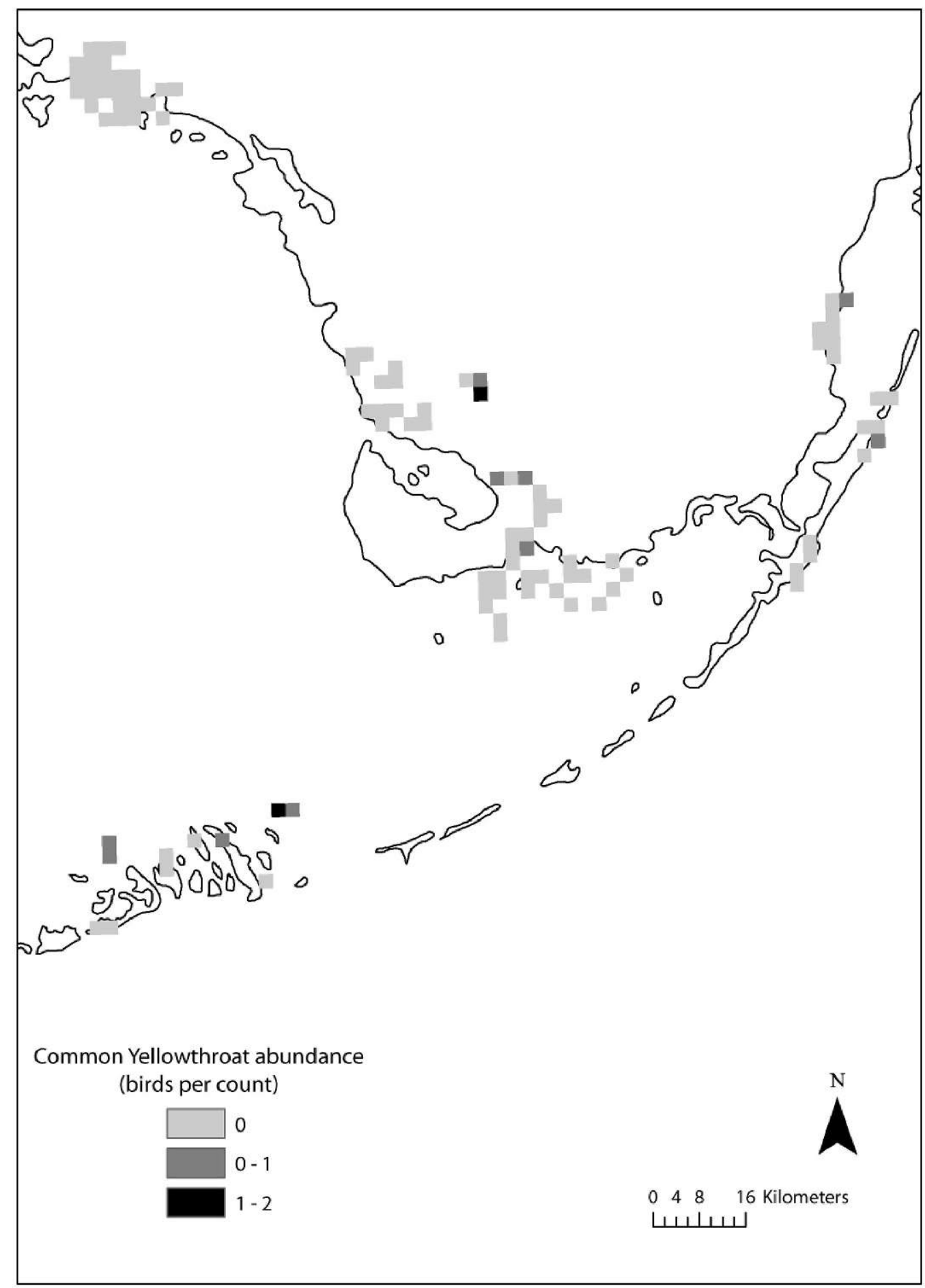

Figure 17. Estimated average abundance of common yellowthroat in mangrove vegetation in southern Florida, as recorded in surveys conducted during May-July, 2008 to 2011.

surveys (Table 3). They occurred in every region of the study area without any apparent regard for variation in the structure of the mangroves (Figure 19). For example, they were as common in the tall mixed forests of the Ten Thousand Islands region as they were on the small islands of Florida Bay or in the short-statured red mangrove shrublands of the lower Keys (Figure 19). The best model 


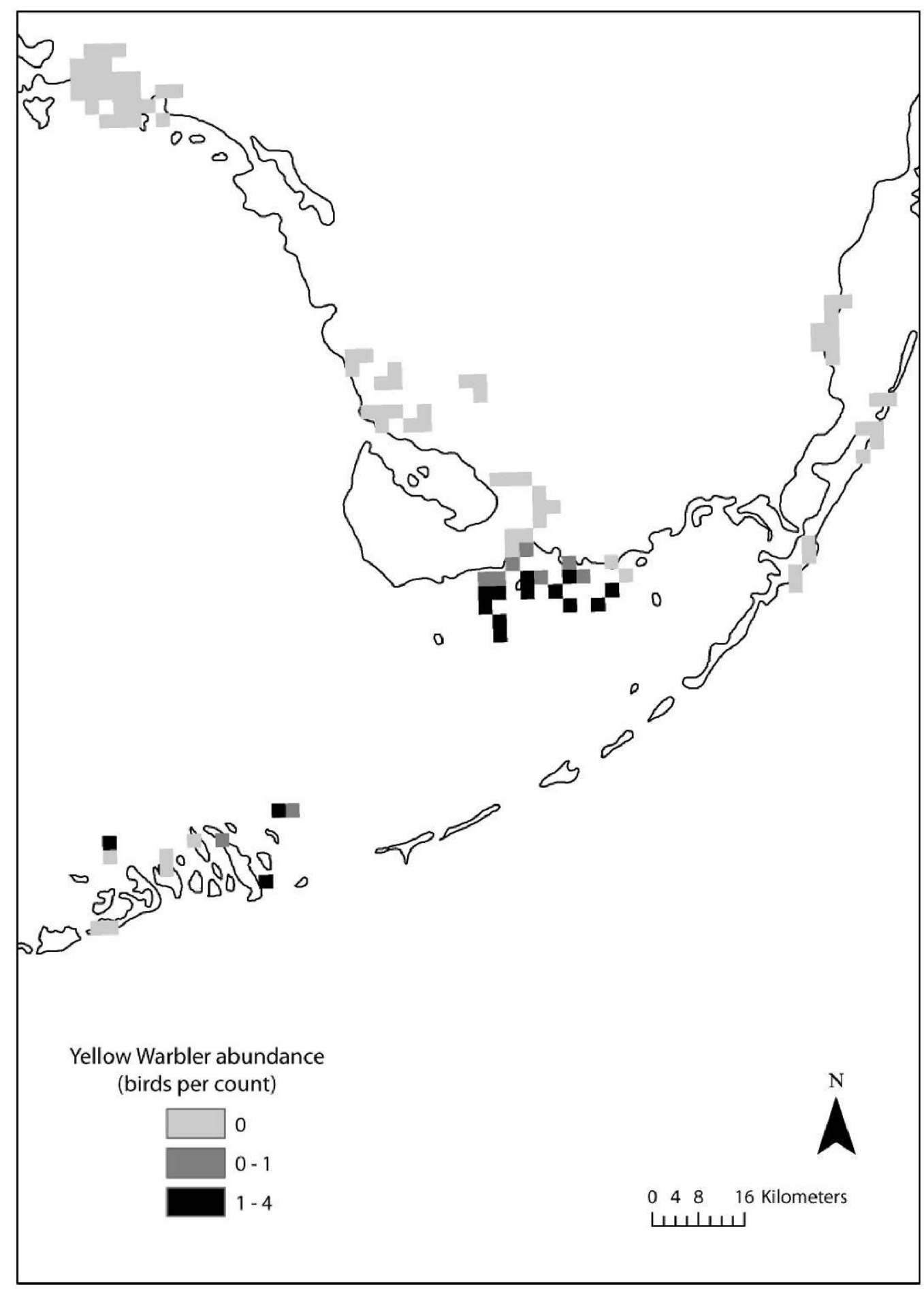

Figure 18. Estimated average abundance of yellow warbler in mangrove vegetation in southern Florida, as recorded in surveys conducted during May-July, 2008 to 2011.

of detectability was $M_{c}$ with data split into 2-min intervals $(\mathrm{min} . \triangle \mathrm{AIC}=37.6)$.

Eastern towhee. Eastern towhees are relatively common in a variety of upland forests in Florida
(Stevenson and Anderson 1994). Robertson and Kushlan (1974), citing unpublished observations, suggested a small population might exist in the mangroves of the southwestern coast. Our data 


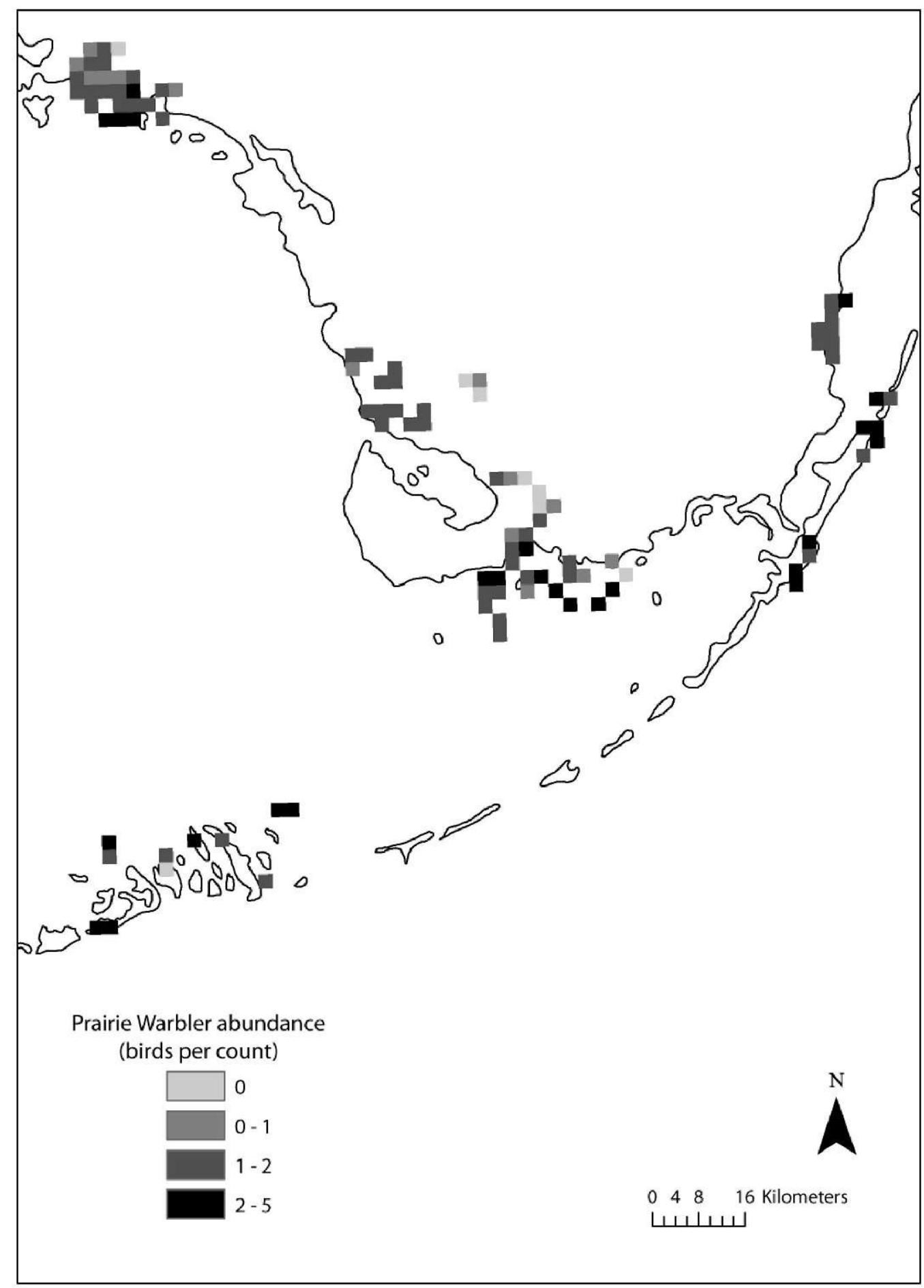

Figure 19. Estimated average abundance of prairie warbler in mangrove vegetation in southern Florida, as recorded in surveys conducted during May-July, 2008 to 2011.

support this observation. We detected a relatively small number of individuals of this species (Table 1), but all 55 detections came at the same nine points in Hell's Bay, Everglades National Park. Multiple individuals were present at each of these points in every year of the study, suggesting the presence of a very small but persistent breeding population. Eastern towhees are a common breeding resident 
of the pine rocklands at Long Pine Key, Everglades National Park, which is $<25 \mathrm{~km}$ distant (Lloyd and Slater 2012). Although the short red mangroves that predominate in Hell's Bay may be structurally similar to the shrubby forest edges occupied elsewhere by this species, the presence of persistent standing water would seem to pose a challenge for a ground-foraging species such as eastern towhee. Additional observations on habitat use and behavior in this population would be of great interest, especially given recent evidence that selective pressures in mangroves may be substantially different than those in adjacent, upland environments (Luther and Greenberg 2011).

Northern cardinal. Northern cardinals are a common breeding species of forest edges and shrubby woodlands from Central America to southern Canada (Halkin and Linville 1999). They are resident year-round throughout their range (Halkin and Linville 1999). In Florida, northern cardinals are common throughout the state, including the Keys (Robertson and Woolfenden 1992). In the present study, northern cardinal was the second most abundant and frequently encountered species in the mangroves (Tables 3 and 4). The islands of Florida Bay most distant from the mainland were the only areas where we did not detect any individuals (Figure 20). The best model of detectability was $M_{c}$ with data split into 2 -min intervals $(\mathrm{min} . \triangle \mathrm{AIC}=$ 64.8).

Red-winged blackbird. A gregarious species of marsh, prairie, and forest edge, red-winged blackbirds are abundant in suitable habitat throughout Florida (Stevenson and Anderson 1994). A large number of subspecies have been recognized (Yasukawa and Searcy 1995), including four in Florida, although Stevenson and Anderson (1994) argued that the variation was clinal and inconsistent.

The best model of detectability was $M_{c}$ with data split into 2-min intervals $(\mathrm{min} . \Delta \mathrm{AIC}=29.9)$. We found red-winged blackbirds at high densities when they occurred, which is to be expected given the semicolonial nesting habits of this species (Tables 3 and 4). Densities were greatest in the Keys and on the islands of Florida Bay, all of which were inhabited save for Big Key (Figure 21). The open, prairie-like depressions at the center of many of the islands in Florida Bay seem to offer attractive breeding habitat for this species. Red-winged blackbirds were far less common on the mainland, reaching intermediate densities at the most inland sites and in the narrow forests along Biscayne Bay (Figure 21). They were absent from the extensive forests along the southwestern coast and much of the Ten Thousand Islands region with the exception of a few points at the ecotone between freshwater marsh and the mangroves. The use of mangroves by redwinged blackbirds appears to be restricted to the drier, shorter, and more open forests and shrublands of the Keys and to areas with extensive forest edge, especially where freshwater marsh or open prairie abuts mangrove forest. Anecdotal evidence in support of this pattern is evident from the J.N. "Ding" Darling National Wildlife Refuge in Sanibel, where a once-robust breeding population (described in Prather and Cruz 2006) disappeared after a large area of freshwater marsh was allowed to revert to mangrove forest (J. Palmer, USFWS, personal communication).

Common grackle. Common grackles are a remarkably adaptable species. Within their range, they breed nearly anywhere that offers suitable nest sites, from the boreal forest of northern Canada through the pine forests and suburban plantings of southern Florida (Robertson and Kushlan 1974; Peer and Bollinger 1997). Common grackles are rarely found in extensive forests, appearing instead to prefer forest edges, marshes, or open woodlands (Peer and Bollinger 1997).

Although not noted in Robertson and Kushlan (1974) as a resident of mangroves, we found common grackles throughout the study area, albeit at low densities (Tables 3 and 4) and with a rather patchy distribution (Figure 22). Detections of common grackles were concentrated in the lower Keys and on the islands of Florida Bay, presumably because mangroves in these areas are patchier and offer more edge habitat. As with red-winged blackbirds, common grackles were not detected in the large, extensive mangrove forests of the southwestern coast. The best model of detectability was $M_{c}$ with data split into 2-min intervals $(\min . \triangle \mathrm{AIC}=12.1)$.

Brown-headed cowbird. Brown-headed cowbirds are a recent addition to the avifauna of Florida, and since their arrival have spread southward throughout the peninsula (Robertson and Woolfenden 1992; Woolfenden and Robertson 2006). Breeding has not been confirmed on the Keys (Robertson and Woolfenden 1992; Prather and Cruz 1996). We detected relatively few brown-headed cowbirds (Table 1), although the detections that we recorded were spread over most of the study area. Six detections occurred at five different points along Biscayne Bay. Single detections were noted at Rowdy Bend in Everglades National Park; Clive, Frank, and Palm keys in Florida Bay; Turtle and Tripod keys in the Ten Thousand Islands region; and, perhaps most significantly, at two points on north Key Largo near Card Sound.

\section{Discussion}

Our goals in conducting this study were to document the species composition of the breedinglandbird assemblage of Florida's mangroves, to quantify the distribution of individual species and examine broad patterns of distribution among species, and to generate baseline estimates of 


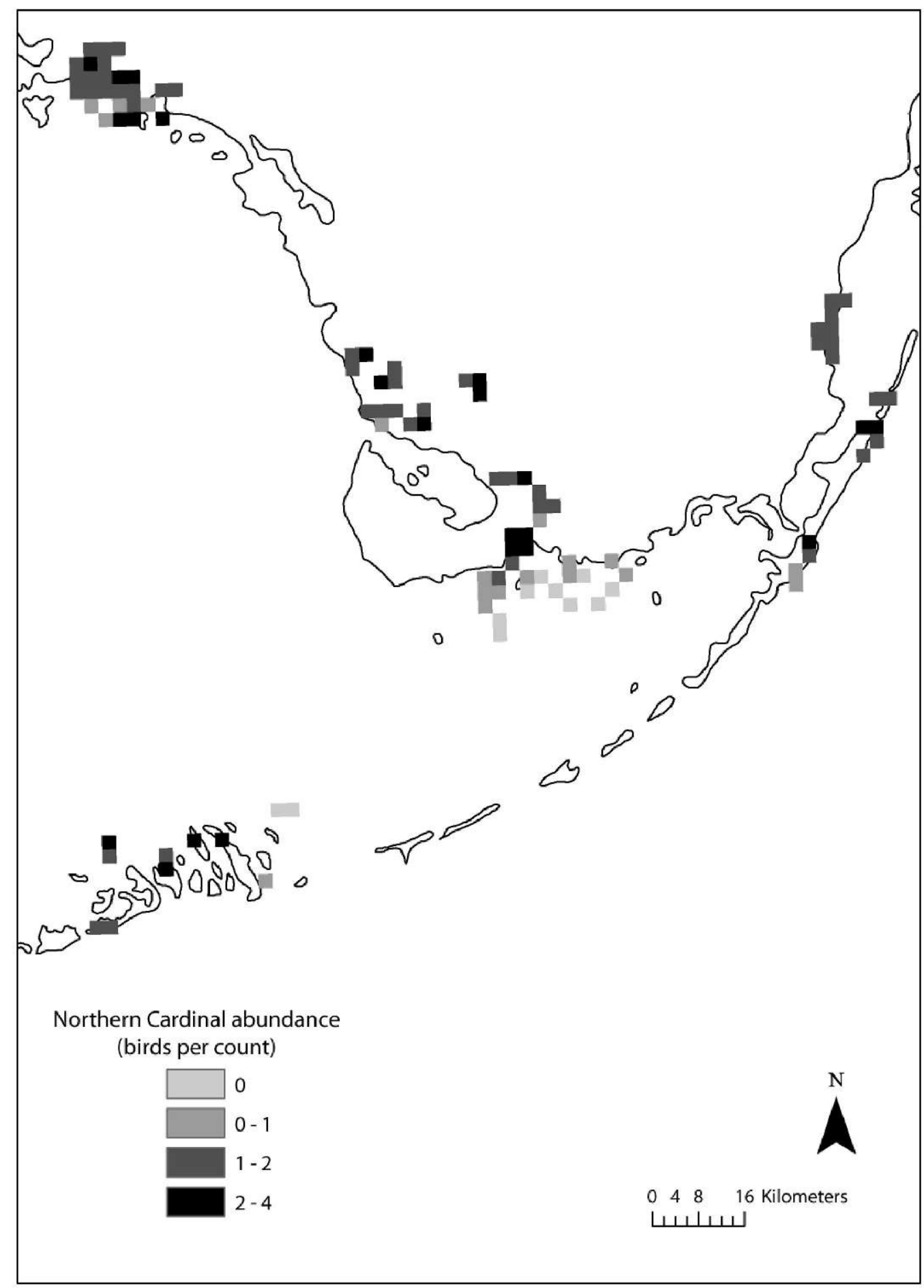

Figure 20. Estimated average abundance of northern cardinal in mangrove vegetation in southern Florida, as recorded in surveys conducted during May-July, 2008 to 2011.

abundance. In this section, we begin by discussing the consequences of limiting our sampling frame to areas that were accessible by boat or foot. We then describe the composition of the avifauna and discuss its possible origins, examine patterns of distribution that collectively define the distribution of the individual species in the avifauna, and finally conclude with a discussion of patterns of abundance 


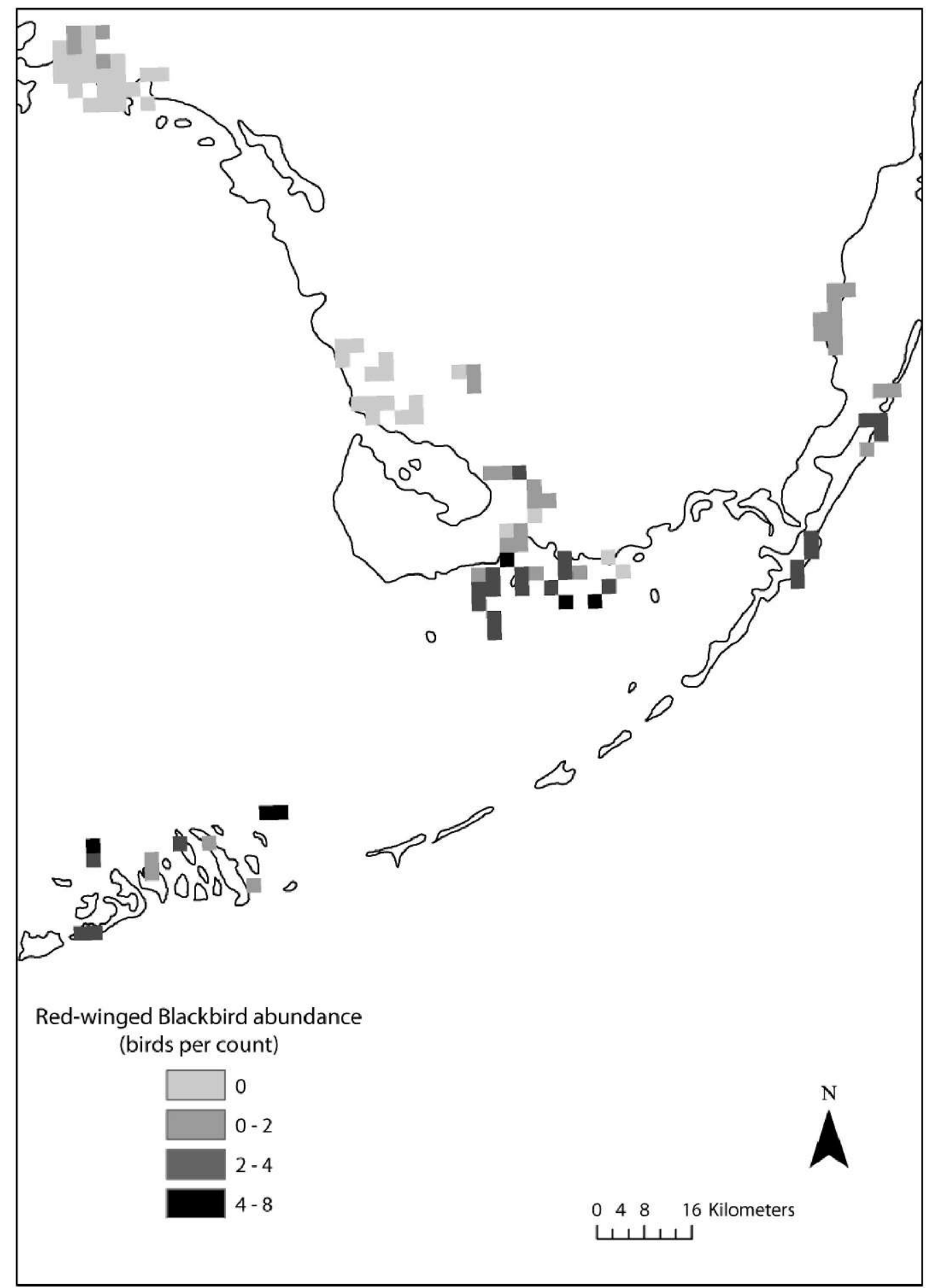

Figure 21. Estimated average abundance of red-winged blackbird in mangrove vegetation in southern Florida, as recorded in surveys conducted during May-July, 2008 to 2011. 


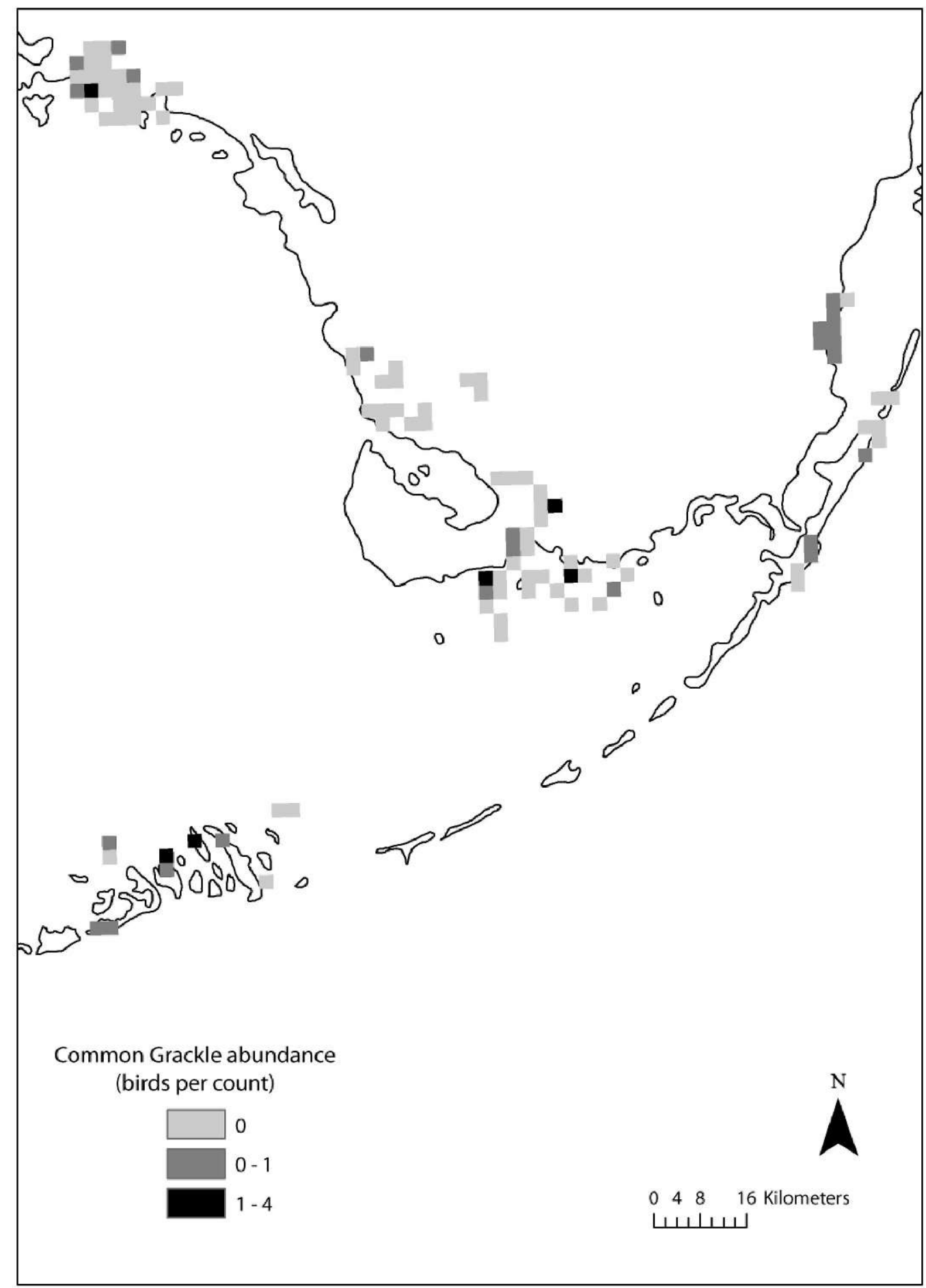

Figure 22. Estimated average abundance of common grackle in mangrove vegetation in southern Florida, as recorded in surveys conducted during May-July, 2008 to 2011. 
and some methodological challenges in the enumeration of mangrove landbirds.

\section{Consequences of a constrained sampling frame}

The difficulty of moving freely through the mangroves limited our ability to sample our target population randomly, and our sampling frame included only areas that we could access by boat or by foot. As a consequence, our sample design does not yield direct inference about the population of interest, which was the breeding-landbird assemblage occupying all of Florida's mangroves. To examine the extent to which characteristics of our constrained sampling frame matched characteristics of the population as a whole, we compared the distribution of land-cover types in our sample and in the population. The proportion of different landcover types in our sampling frame was roughly proportional to the distribution of land-cover types found across the mangroves as a whole, although we apparently oversampled forest types found near the coast and along tidal creeks while undersampling the freshwater marsh mangrove ecotone. Undersampling the ecotone would tend to produce estimates of abundance that were biased upward, because both the number of species and the number of individuals at points along the freshwater marshmangrove ecotone tended to be low. We did not sample at all from the interior of large forest patches that were not traversed by tidal creeks; we are uncertain how this would influence the accuracy of our estimates, but presumably any effect would be species-specific (e.g., producing underestimates of abundance of species favoring interior forest). In any case, given that Florida's mangroves are generally patchy and dominated by edge environments, the potential bias introduced by sampling along edges, as we did, is probably smaller than the bias introduced by undersampling particular vegetation types.

\section{Species composition and origins of the avifauna}

The landbird avifauna of Florida's mangroves, like most biological assemblages, is composed of many rare species and relatively few common species (Hubbell 2001). Like other mangrove bird assemblages around the world, a handful of species account for the vast majority of all detections (e.g., Noske 1996). As is generally true, the common species were also widespread (e.g., Brown 1984). Systematic surveys of landbird assemblages in mangroves in the West Indies are lacking, so placing Florida's mangrove-landbird assemblage in context is difficult. Little information is available about the birds of Cuba's mangroves. Mangroves in the Bahamas, another possible source of colonists to
Florida's mangroves, appear to support a similar, but less diverse, assemblage of breeding landbirds (Northrop 1891; Allen 1905; Buden 1987, 1990, 1992a, 1992b). Indeed, Florida's mangroves probably host a greater number of breeding species, and likely a greater density of individuals, due to the significant temperate element present in Florida.

Perhaps the best documentation of a mangrove avifauna in the West Indies is that of Acevedo and Aide (2008), working in Puerto Rico. Although Puerto Rico's mangroves are probably not a direct source of colonists for Florida's mangroves, the results presented by Acevedo and Aide (2008) may shed some light on landbird assemblages in mangroves on the species-rich islands in the West Indies, including Cuba, which is a source of colonists of Florida's mangroves. The relatively tall whitemangrove forests on Puerto Rico supported relatively few breeding species (17) but at much higher apparent densities than we found in Florida's mangroves. The species composition was relatively similar to that observed in our study area. Whitecrowned pigeon, common ground-dove, mangrove cuckoo, gray kingbird, and black-whiskered vireo were all present in the mangroves of Puerto Rico. As with the mangroves of the Bahamas, Puerto Rican mangroves appear somewhat less species-rich than Florida's mangroves because of the lack of any species of temperate origin.

Many of the species unique to the mangrove forest surveyed by Acevedo and Aide (2008) had apparent analogues in the mangroves of Florida, suggesting some degree of regularity in the partitioning of niche space. Four of these analogues are cogeneric replacements: the red-bellied woodpecker was replaced by the Puerto Rican woodpecker Melanerpes portoricensis, the great crested flycatcher by the Puerto Rican flycatcher Myiarchus aniillarum, the common grackle by the Greater Antillean grackle Quiscalus niger, and the brown-head cowbird by the shiny cowbird Molothrus bonariensis. Unlike Florida, the mangroves in Puerto Rico also provided habitat for a thrush (red-legged thrush Turdus plumbeus) and the ubiquitous bananaquit Coereba flaveola. Bananaquits, which also occur in mangroves in the Bahamas, have been observed numerous times in Florida (Woolfenden and Robertson 2006), but have yet to establish a breeding population.

In terms of species composition, the breeding landbirds of the mangroves provide an example of a biogeographic condition common across much of southern Florida, in which an essentially temperate fauna inhabits a largely tropical flora (de Pourtales 1877; Robertson and Kushlan 1974). Of the 18 most frequently detected taxa, only 5 have primarily Neotropical distributions: black-whiskered vireo, white-crowned pigeon, mangrove cuckoo, gray kingbird, and Cuban yellow warbler. In addition, 
the Florida prairie warbler is endemic to the mangroves of Florida. At least two nonexclusive hypotheses may explain this pattern of dominance by temperate bird species.

First, as put forth by Robertson and Kushlan (1974), the predominance of temperate birds may reflect the relative recent time during which tropical conditions have developed on the peninsula. In other words, the current fauna is a reflection of Florida's long history as a temperate landmass, whereas its current flora is a reflection of its increasingly tropical conditions. During most of the past $20,000 \mathrm{y}$, peninsular Florida was a much larger landmass because of markedly lower sea levels and was far colder and more arid than at present, and supported plant assemblages now characteristic of areas much farther north Watts 1971, 1980; Emslie 1998). Pollen records for southern Florida are scant, but in central and northern Florida modern-day plant assemblages appear to have arisen only within the past 5,000 7,000 y (Watts and Hansen 1994). The avifauna that developed during this period of temperate conditions was composed largely of species derived from the Nearctic; most of the Neotropical species that colonized Florida earlier in the Pleistocene disappeared in the late Pleistocene, presumably because climatic conditions deteriorated in the face of advancing continental glaciers (Emslie 1998). Circumstantial evidence exists that temperate Florida has been exporting species to the West Indies for a much longer time than the West Indies have been returning species to the continent, further supporting the notion of a long temperate history for southern Florida Robertson and Kushlan 1974; Woolfenden and Robertson 2006). Many of the temperate species that have colonized the Bahamas, for example, have differentiated either to form endemic subspecies, as in the case of brown-headed nuthatch Silla pusilla insularis, hairy woodpecker Picoides villosus maynardi and $P$. v. piger, and pine warbler Selophaga pimus achrustera, or wholly new species, as in Bahama yellowthroat Geothlypis rostrata and Bahama warbler Setophaga flavescens. Conversely, none of the recent West Indian colonists of Florida are substantially differentiated from source populations (Robertson and Kushlan 1974). All things being equal, the extent to which colonists have diverged from source populations should reflect the amount of time since colonization.

Although it is almost certain that Florida was covered largely by temperate vegetation types during most of the Pleistocene, whether mangroves have persisted on the coastline of Florida through the glacial cycles of the Pleistocene is unknown. Peat from the Florida Keys that was identified as belonging to either red or black mangrove has been dated to approximately 9,000 y before present (Toscano and Macintyre 2003), but it is unclear whether mangroves were present on a now-submerged coasline before that time. Sherrod and MacMillan (1985) speculated that mangroves disappeared from Florida and the Gulf of Mexico during the Pleistocene and recolonized from Cuba as glaciers retreated. Under this scenario, the assemblage of birds presently breeding in Florida's mangroves may have been organized only within the past $10,000 \mathrm{y}$. A temperate avifauna dominated Florida during that time period, and it is these species, presumably preadapted to the conditions afforded by the mangroves, that would have been poised to colonize the mangrove forests and shrublands developing on the early Holocene coastline of Florida. West Indian species capable of surviving in the mangroves of Florida colonized at a slower rate, both because they faced a substantial water barrier that birds of the continent did not and perhaps because individuals in island populations have reduced competitive and dispersal abilities (e.g., MacArthur and Wilson 1963). Under this scenario, we would expect that the West Indies would continue to provide additional colonists to the mangroves of Florida, whereas deteriorating climatic conditions (i.e., warming) would force the retreat of poorly adapted temperate species.

Under the hypothesis that the dearth of tropical birds in the mangroves of Florida is due to Florida's recent history as a temperate landmass, then we would predict a future avifauna with more Neotropical representatives and fewer temperate representatives. Of course we cannot provide a rigorous test of this hypothesis, but we note that the only recent colonization of the mangroves - that of the Cuban yellow warbler, essentially reinvading the continent of its ancestor-proceeded from the West Indies to Florida. The West Indian race of mourning dove, Z. m. macroura, is also a recent colonist of the Keys, although it is not by any means limited to mangroves (Stevenson and Anderson 1994). Black-whiskered vireo may also be a recent (i.e., 19th century) colonist from the West Indies, although this event can only be inferred from an absence of records prior to 1848 (Stevenson and Anderson 1994).

The second hypothesis for the current composition of the mangrove avifauna is not that suitable habitat has been lacking in Florida, but that West Indian birds have had difficulty invading that state's mangrove forests. Although direct evidence is lacking, mangrove forests may have been present on the coastline of Florida throughout the Pleistocene, in which case the lack of West Indian species may reflect either poor dispersal abilities or weak competitive abilities of island birds. For example, the estimated age of the Florida prairie warbler approximately $70,000 \mathrm{y}$-might argue for a longer history of mangroves in Florida than do palynological records, although its current restriction to 
mangroves does not necessarily mean it has always been limited to mangroves (Buerkle 1999). Both theoretical considerations (e.g., Bellemain and Ricklefs 2008) and the large number of West Indian species recorded as vagrants in southern Florida ( $n=32$; Woolfenden and Robertson 2006) argue against dispersal as the sole factor limiting the spread of Neotropical species into the mangroves of southern Florida. An inability to compete eflectively with mainland species may play a role, although it was discounted by Robertson and Kushlan (1974). Whereas all of the landbird species to have colonized the Bahamas and Cuba from Florida occupy similar habitats on the mainland and in the islands (e.g., brown-headed nuthatch, hairy woodpecker, pine warbler, and blue-gray gnatcatcher are most common in pine forests in both Florida and the Bahamas), most of the landbirds that have colonized Florida have either shifted or shrunk the breadth of habitats that they occupy, suggesting competitive exclusion by continental species. Black-whiskered vireo, for example, is found in a variety of forests over a 1500-m elevation range in Jamaica (Cruz 1980), but in Florida is found only occasionally outside of the mangroves. Mangrove cuckoo is similarly widespread in the Bahamas and on other islands in the West Indies, and in fact shows no preference for mangroves over other forest types (Robertson 1962, Brudenell-Bruce 1975). In Florida, it is limited to the mangroves.

Another possibility, raised during review of an earlier version of this manuscript, is that West Indian species in general lack the life-history or behavioral traits needed to cope with the more diverse assemblage of nest predators found on mainland Florida. More intense predation pressure would limit the viability of any newly founded population, and, if we assume that mangroves support fewer nest predators than other mainland habitats, would also explain why West Indian species appear to occupy a narrow range of habitats in the United States. A serious evaluation of this hypothesis, however, awaits data on nest survival of populations in mangrove forests of Florida and in the West Indies.

None of these hypotheses are exclusive of the others, and indeed it is likely that the present-day predominance of temperate species in Florida's mangroves reflects past climate history, limitations on dispersal, and biotic interactions such as predation and competition. Because of the depth of the Florida Straits neither Cuba nor the Bahamas were appreciably closer to the coast of Florida even at the most extreme sea-level minima, and so potential colonists from the West Indies have always faced a large water barrier (Cay Sal Bank, which would have been much larger during glacial maxima, would have provided the only stepping stone between Cuba and Florida). Even if some mangroves persisted in Florida during the last glacial maximum, any colonist that managed to reach these mangroves would have encountered cooler and more arid environmental conditions as well as a host of potential competitors and predators in the form of temperate species pushed south in advance of the glacial ice. All told, present-day conditions in Florida's mangroves are probably more suitable for West Indian colonists than at any other time in history.

\section{Patterns of distribution}

The relatively narrow strip of Florida's southern coastline covered by mangroves marks both a northward and southward front: several temperate bird species reach their southern range limit in the mangroves of peninsular Florida, and several West Indian species reach their northern range limit in the Keys and islands of Florida Bay. In some cases, these boundaries probably reflect recent colonization events. For example, Cuban yellow warblers are restricted to the Keys and islands of Florida Bay, even though no obvious habitat factors limit their continued northward spread. The observed distribution of Cuban yellow warblers may reflect the recent history of colonization from the south, and in the future we might expect to find this subspecies breeding along the southern coast of the mainland. The West Indian subspecies of mourning dove may represent a similar biogeographic constraint. If the individuals that we detected in the Keys belong to this race, then their restricted distribution may reflect fairly recent colonization of Florida from the West Indies.

In other cases, the distributions that we observed probably reflect habitat-related constraints. Pileated woodpeckers decline in abundance from the Ten Thousands Islands region to the southwestern coast, and are only infrequent visitors to the Keys. Their scarcity in the southern reaches of Florida's mangroves is most likely a consequence of the decline in tree size from north to south and the subsequent lack of suitable nesting sites. Conversely, white-crowned pigeons are likely limited to Florida Bay and the Keys by the joint distribution of predator-free islands and poisonwood, a key food species. Although they did not show any clear pattern of distribution from north to south, both common yellowthroat and red-winged blackbird appeared to be distributed according to their shared preference for shrubby marshes. Several other temperate species Carolina wren, eastern towhee, and American crow, in particular-reach their southern range limit in the mangroves of peninsular Florida. Although apparently suitable vegetation occurs farther south, we speculate that these species are also limited by habitat conditions, although the nature of that limitation is unclear. 
Some species showed no such boundaries within the study area. Red-bellied woodpecker, northern cardinal, Florida prairie warbler, and white-eyed vireo were not obviously limited by habitat or larger biogeographic processes (e.g., ongoing range expansion). Members of this group were detected in all regions of the study area and at $>75 \%$ of all survey points, and were typically found at relatively high density. No obvious distributional breaks were apparent for great crested flycatcher, black-whiskered vireo, red-shouldered hawk, and mangrove cuckoo, either, although species in this group were found at somewhat lower densities and at far fewer points. Given the difficulty in detecting mangrove cuckoos during passive surveys, we are hesitant to draw conclusions about the distribution of this species in the mangroves, because continued surveys would likely reveal a very different pattern of occupancy.

\section{Patterns of abundance and challenges in the enumeration of mangrove landbirds}

The density of landbirds is strikingly low in all habitats in southern Florida (Robertson 1955; Emlen 1978). Density of landbirds in mangroves is often, but not always, lower than in adjacent habitats (Cox and Ricklefs 1977; Emlen 1977; Salgado-Ortiz et al. 2008). We found very low densities of landbirds in comparison with studies conducted in other forest types (e.g., Kendeigh 1944) and even in comparison to studies that we conducted in nearby pine forests of southern Florida (Lloyd and Slater 2011, 2012). Pine forests are the only other widespread native forest environment in southern Florida, and many of the landbirds that breed in the pines also breed in the mangroves. Using the same methodology to estimate density (see Lloyd and Slater [2011, 2012] for details of pineland bird surveys), we found that landbirds in the pine forests of southern Florida occurred at nearly 1.5 times the density (2.4 individuals $\mathrm{ha}^{-1}$; $95 \%$ CI $=2.2-2.7$ individuals $\mathrm{ha}^{-1}$ ) of that observed in the mangroves (Table 3). In part, the low overall density of landbirds in the mangroves is a reflection of the relatively low species richness: the median number of species detected during a 10-min point count in the mangroves was five (mean $=5.0$; $95 \%$ CI of the mean $=4.95 .1)$, whereas the median in the pines was six ( mean $=5.8 ; 95 \% \mathrm{CI}$ of the mean $=5.7-6.0$ ). The species that occur only in mangroves tended to exist at relatively low densities, whereas we (Lloyd and Slater 2011, 2012) found the species that occur in pinelands but not mangrovesmost notably pine warbler Selophaga pinus, brownheaded nuthatch Sitta pusilla, and blue-gray gnatcatcher Polioptila caerulea - at much higher densities. Of the species that occur in both habitats during the breeding season, only white-eyed vireo, red-winged blackbird, American crow, and pileated woodpecker were more abundant in the mangroves. Red-bellied woodpecker, downy woodpecker, northern cardinal, common yellowthroat, red-shouldered hawk, Carolina wren, great crested flycatcher, blue jay, eastern towhee, northern llicker, and mourning dove all occurred at greater densities in the pine forests.

Luther and Greenberg (2011) suggested that mangroves might function like islands, whereby low species richness would lead to density compensation (e.g., Crowell 1962; MacArthur et al. 1972) and niche expansion. We found that the landbird assemblage in Florida's mangroves was species-poor, but we found no evidence of density compensation. Overall population density of landbirds in the mangroves was lower, not higher, than in nearby pine forest, and most species that occurred in both habitats either were more common in pines or showed no difference in density.

Density compensation is thought to arise when changes in species richness result in reduced pressure from competitors or predators (c.g., Case 1975; McGrady-Steed and Morin 2000). For example, birds on islands may forage or nest in a broader range of habitats when certain competing species are absent, and in doing so, access more resources and attain a greater population density. However, if changes in species richness are brought about by changes in resource availability, and not by colonization extinction dynamics, then density compensation may not arise. For example, species richness and density both may be low in mangroves because mangroves offer a relatively homogenous environment with few opportunities for partitioning critical resources such as nest sites and foraging locations. Alternatively, species richness and overall density may be low because some niches remain unfilled, for example as might be the case if mangroves are relatively recent colonists of Florida and are still accumulating species. Prather and Cruz (1995) showed that Florida prairie warblers and Cuban yellow warblers, where they occurred in sympatry, foraged and nested at different heights, suggesting that the landbird assemblage could accommodate the addition of new species. However, densities of the two species were inversely related to one another, which could reflect either differences in habitat preference or density compensation between competitors.

The assemblage of birds breeding in Florida's mangroves includes several species not found elsewhere in North America, and so is of interest from a conservation standpoint. Our estimates of population size in the mangroves of Florida, although subject to several important caveats, indicate fairly large populations for most of the mangrove specialists. The species of greatest concern is mangrove cuckoo, with a rather small estimated population size of 6,446 
(close to the Partners in Flight U.S. population size estimate of 6,100 individuals; Rich et al. 2004). The estimates of population size may have some value in prioritizing species for conservation, although we caution that in generating them we have applied our density estimates to situations outside of our sampling frame. Our sample included a disproportionately large amount of red-mangrove forest, and a disproportionately small amount of dwarl mangrove, and thus by extrapolating our density estimates to all of Florida's mangroves we have likely overestimated population sizes of species associated with the coastal and riverine areas that supported red-mangrove forest and underestimated population sizes of species associated with dwarf mangrove. Dwarf mangroves tended to support relatively few species and relatively few individuals, and so undersampling these areas may have produced abundance estimates that are biased high. A more valuable use of the estimates of population size may be as a baseline against which the results of future monitoring may be compared.

At present, populations of mangrove landbirds are not monitored in any systematic fashion. Implementing a comprehensive, dedicated program for monitoring mangrove landbirds would require hiring or assigning personnel to maintain and update a database, conduct surveys, analyze data, and prepare reports and publications. Doing so requires a consistent source of funding, which is unlikely given current and expected future budget constraints. We see two other options for keeping tabs on populations of mangrove landbirds even if a dedicated, rangewide monitoring program cannot be implemented in the short term. The first is to expand Breeding Bird Survey (BBS) routes and the second is for individual administrative units with the interest and resources to pursue monitoring on a smaller scale.

Only five active BBS routes sample mangroves (Punta Gorda, Flamingo, and Card Sound, Weaver Station, and Sugarloaf Key 2), and most stops on these routes sample other habitats. Four other routes located in coastal southern Florida were discontinued primarily because increased traffic made surveys unsafe. Adding BBS routes is diflicult given constraints on route placement (e.g., randomization) and the lack of roads within mangroves. However, the BBS does include nonrandom routes (" 900 " series) established to monitor birds on public lands, and although the U.S. Geological Survey does not include data from 900 series routes in its annual trend analysis, data are managed and available for other users. In addition, nonrandom routes can consist of disjunct sections a necessity for expanding BBS routes in mangroves given the lack of long, continuous sections of road and can include portions conducted by boat (K. L. Pardieck, BBS National Coordinator, personal communication). The flexibility of nonrandom routes would facilitate surveys in these relatively inaccessible habitats and, when combined with the use of volunteer observers, would help overcome the lack of resources available to support new monitoring efforts.

Individual monitoring programs implemented in a particular protected area may also have value. As shown by Lloyd and Doyle (2011), even local and small-scale monitoring programs can be useful in providing early warning of problems that may eventually reach populations throughout the mangroves. The advantage of this approach is that it allows some level of monitoring even if a range-wide program proves unviable and allows for more local control over the objectives of the effort (e.g., monitoring can be tailored to examine the response of populations to local management actions). The potential disadvantages are that it can lead to data that are not comparable between different sites and can result in many small, independent efforts, none of which have sufficient power to detect biologically important trends range-wide. If individual agencies or organizations pursue small-scale monitoring efforts, we encourage them at the very least to adopt a unified approach to conducting surveys. J. N. "Ding" Darling National Wildlife Refuge and Ten Thousand Islands National Wildlife Refuge have each implemented local monitoring efforts that share a common set of protocols, and these may serve as a model for managers at other protected areas interested in monitoring the health of mangrove-landbird populations.

Despite the challenges that face any effort to craft and implement a long-term monitoring program for mangrove landbirds, there are many good reasons to do so. Florida's mangroves host a unique avifauna. Many of the breeding species occur nowhere else in North America. Despite the reputation for elusiveness and rarity associated with this group of birds, only mangrove cuckoos appear truly uncommon. Some of the mangrove-dependent species are widespread and abundant, and most are abundant in at least some parts of the mangroves. Nonetheless, recent declines of mangrove cuckoos and blackwhiskered vireos in the Ten Thousand Islands area (Lloyd and Doyle 2011) caution against complacency in the face of incomplete information.

Unlike mangroves in much of the world, which are being destroyed at a rapid pace, all of the remaining large stands of mangrove in Florida are administratively protected, which augurs well for the birds that inhabit these forest and shrublands. Along with the need for population monitoring, the greatest immediate challenge in conserving this assemblage is to develop a better understanding of how activities outside of the mangroves, such as mosquito control or changes in freshwater flows, affect bird populations within the mangroves. Over 
the long term, the greatest challenge will be to ensure that mangroves are able to move inland in response to rising sea levels. Mangroves are capable of adapting to large changes in sea level-witness their response to sea-level changes since the last glacial maximum-but anthropogenic barriers may retard or preclude their ability to do so.

\section{Acknowledgments}

This work was funded by Florida Fish and Wildlife Conservation Commission, Ten Thousand Islands National Wildlife Refuge, and Everglades National Park. We gratefully acknowledge the support and assistance provided by our agency collaborators, including E. Alvear (Biscayne National Park), S. Bass (Everglades National Park), and J. Palmer (Ten Thousand Island National Wildlife Refuge). The early and persistent efforts of T. Doyle (USFWS) and K. Miller (Florida Fish and Wildlife Conservation Commission) were instrumental in generating support for our research. We thank both editors and two anonymous reviewers for suggesting many improvements to earlier drafts of this manuscript.

Any use of trade, product, or firm names is for descriptive purposes only and does not imply endorsement by the U.S. Government.

\section{References}

Accvedo MA, Aide TM. 2008. Bird community dynamics and habitat associations in karst, mangrove and Ptcrocarpus forcst fragments in an urban zone in Puerto Rico. Caribbean Journal of Science 44:402-416.

Aldrich JW, Duvall AJ. 1958. Distribution and migration of races of the mourning dove. Condor 60:108-128.

Allen GM, 1905. Summer birds in the Bahamas. Auk 22;113-133.

Bancroft GT, Bowman R. 1994. Temporal patterns in dict of nestling white-crowned pigeons: implications for conservation of frugivorous columbids. Auk 111:844 852.

Bancroft GI; Bowman R. 2001. White-crowned pigeon (Patagivenas leucocephala). Account 596 in Poole A, editor. The birds of North America onlinc. Ithaca, Ncw York: Corncll Iab of Ornithology. Available: http://bna.birds.corncll.cdu/bna/species/596 (Fcbruary 2014)

Bancroft GI, Bowman R, Sawicki RJ. 2000. Rainfall, fruiting phenology, and the nesting season of white-crowned pigeons in the upper 1lorida Keys. Auk 117:416 426.

Bancroft Gl', Strong AM, Carrington M. 1995. Deforestation and its effects on forest-nesting birds in the Florida Kcys. Conservation Biology 9:835-844.

Banks RC, Hole J. 1991. Taxonomic review of the mangrove cuckoo, Coccyzus minor (Gmelin). Caribbean Journal of Science 27:54 62 .

Barrantes G. 1998. Reproductive activity of birds in a mangrove swamp in Northwest Costa Rica. Revista de Biologia Tropical 46:1163-1166.

Bcllcmain F, Ricklefs RF. 2008. Arc islands the end of the colonization road? 'Trends in Lcology \& Evolution 23:461-468.

Bivand RS, Pebesma LJ. Gomez-Rubio V. 2008. Applied spatial data analysis with R. New York: Springer.

Bond J. 1942. Additional notes on West Indian birds. Procecdings of the Academy of Natural Sciences of Philadelphia 94:89-106.

Bowman R. 2002. Common ground-dove (Columbina passerina). Account 645 in Poolc A, cditor. The birds of North Amcrica onlinc. Ithaca, New York: Corncll T ab of Ornithology. Available: http://bna.birds.comell.edu/bna/species/645 (l'ebruary 2014).

Brown JH. 1984. On the relationship between abundance and distribution of spccics. Amcrican Naturalist 124:255-279.

Brudencll-Bruce P. 1975. The birds of the Bahamas. New York: Taplinger.
Buden DW, 1987. The birds of Cat Island, Bahamas. Wilson Bulletin 99:579 600.

Buden DW. 1990. 'The birds of Rum Cay, Bahama Islands. Wilson Bulletin 102:451-468.

Buden DW. 1992a. The birds of Long Island, Bahamas. Wilson Bullctin 104:220-243.

Buden DW. 1992b. The birds of the Lxumas, Bahama lslands. Wilson Bulletin 104:674 698.

Buerkle CA. 1999. The historical pattern of gene flow among migratory and nommigratory populations of prairie warblers (Aves: Parulinac). Fvolution 53:1915-1924.

Bucrklc CA. 2000. Morphological variation among migratory and non-migratory populations of prairic warblers. Wilson Bullctin 112:99-107.

Cadman MD, Sutherland DA, Beck GG, Lepage D, Couturier AR. 2007. Atlas of the breeding birds of Ontario, 2001-2005. Toronto: Ontario Naturc.

Gase TJ. 1975. Species numbers, density compensation, and colonizing ability of lizards on islands in the Gulf of California. Lcology 56:3-18.

Chace Jl, Woodworth BL, Cruz A. 2002. Black-whiskered vireo (Vireo altiloquus). Account 607 in Poole A, editor. The birds of North America onlinc. Ithaca, Ncw York: Cornell Iab of Ornithology. Available: http://bna.birds.corncll.cdu/bna/species/607 (Fcbruary 2014).

Cox GW, Ricklefs RF. 1977. Species diversity and ccological release in Caribbean land bird faunas. Oikos 28:113-122.

Cox J. 2006. Part II: trends in breeding distributions based on l'lorida's breeding bird atlas project. Pages 71-140 in Noss Rli, cditor. The brecding birds of Florida. Gainesvillc, Florida: Florida Ornithological Socicty.

Growell KI.. 1962. Reduced interspecific competition among the birds of Bermuda. Lcology 43:75 88.

Cruz A. 1980. leeding ecology of the black-whiskered vireo and associated gleaning birds in Jamaica. Wilson Bulletin 92:40-52.

Davis JH. 1940. The ccology and gcologic role of mangroves in Florida. Publications of the Carnegic Institution of Washington 32:303-412.

Davis JH. 1943. 'The natural features of southern Florida, especially the vegetation, and the Lverglades. Florida Geological Survey Geological Bulletin 25:1-311.

Diamond AW. 1980. Fcology and species turnover of the birds of Iittlc Cayman. Atoll Rescarch Bulletin 241:141-164.

Donovan TM, Beardmore CJ, Bonter DN, Brawn JD, Cooper RJ, Fitzgerald JA, Ford R, Gauthreaux SA, Gcorgc TI, Hunter WC, Martin 'L', Price J, Rosenberg KV, Vickery PD, Wigley IB. 2002. Priority research needs for the conservation of Neotropical migrant landbirds. Journal of Field Ornithology 73:329-339.

Doyle TW, Girod GF, Books MA. 2003. Modeling mangrove forest migration along the southwest coast of Florida under climatc change. Pages 211-221 in Ning ZH, 'Turner RE, Doyle 'I', Abdollahi KK, editors. Integrated assessment of the climate change impacts on the Gulf Coast region. Baton Rouge, Iouisiana: Gulf Coast Climatc Changc Assessment Council and Iouisiana State University Graphic Services.

Dykstra CR, Hays JI, Crocoll ST. 2008. Red-shouldered hawk (Buteo lineatus). Account 107 in Poolc A, cditor. The birds of North America online. lthaca, New York: Cornell Lab of Onithology. Available: http://bna.birds.cornell.edu/bna/ species/107 (l'ebruary 2014).

Finlen JT. 1977. I and bird communitics of Grand Bahama Island: the structure and dynamics of an avifauna. Ornithological Monographs 24:1-129.

Lmlen J1. 1978. Density anomalies and regulatory mechanisms in land bird populations on the llorida peninsula. American Naturalist 112:265-286.

Fmslic SD. 1998. Avian community, climate, and sea-level changes in the Plio-Pleistocene of the Florida peninsula. Ornithologica Monographs 50:1-113.

larnsworth GL, Pollock KH, Nichols JD, Simons IR, Hines JE, Sauer JR. 2002. A removal model for estimating detection probabilities from point-count surveys. Auk 119:414 425.

lriez RD, Mullin SM, Lloyd JD. 2012. Responsiveness of mangrove cuckoo (Coccyzus minor) during call-playback surveys in southern Florida. Southeastern Naturalist 11:447-454. 
Greene LR. 1942. Golden warbler nesting in lower l'lorida Keys. Auk 59:114-114.

Guzy MJ, Ritchison G. 1999. Common yellowthroat (Geothlypis trichas). Account 448 in Poole A, editor. The birds of North America onlinc. Ithaca, Ncw York: Corncll Iab of Ornithology. Available: http://bna.birds.corncll.cdu/bna/species/448 (Fcbruary 2014).

Haggerty 'TM, Morton ES. 1995. Carolina wren (Throothoru ludovicianus). Account 188 in Poole A, editor. The birds of North America online. Ithaca, New York: Comell Lab of Onithology. Available: http://bna.birds.cornell.edu/bna/specics/188 (Fcbruary 2014).

Halkin ST, Tinville SU. 1999. Northern cardinal (Cardinalis cardinalis). Account 440 in Poole A, editor. The birds of North Amcrica onlinc. Ithaca, Ncw York: Comell Iab of Ornithology. Available: http://bna.birds.conell.edu/bna/species/440 (liebruary 2014).

Heald L.J, Odum WL. 1970. The contribution of mangrove swamps to Florida fisheries. Proccedings of the Gulf and Caribbean Fishcrics Institute 22:130-135.

Hijmans RJ, van Etten J. 2011, raster: gcographic analysis and modeling with rastcr data. $\mathrm{R}$ packagc version 1.9-55. http:// cran.r-project.org/package= raster

Hopp SL, Kirby A. Boone CA. 1995. White-eyed vireo (Vireo griseus). Account 168 in Poole A, editor. 'The birds of North America onlinc. Ithaca, Ncw York: Comell I ab of Ornithology. Available: http://bna.birds.corncll.cdu/bna/species/168 (Fcbruary 2014 ).

Howell AH. 1930. Description of a new subspecies of the prairic warbler, with remarks on two other unrecognized lilorida races. Auk 47:41-43.

Howell AH. 1932. llorida bird life. New York: Coward-McCann.

Hubbcll SP. 2001. The unified ncutral theory of biodiversity and biogcography. Princeton, New Jerscy: Princeton University Prcss.

Hughes JM. 1997. Mangrove cuckoo (Cocc)zus minor). Account 299 in Poole A, editor. The birds of North America Online. Ithaca, New York: Cornell Lab of Onithology. Available: http://bna. birds.cornell.edu/bna/species/299 (lebruary 2014).

Karim A. 2007. Status and usc of tropical hardwood hammock and forested residential arcas as habitat for resident and Ncotropical migratory birds in the Florida Kcys. Master's thesis. Gainesville: University of Florida.

Kendeigh SC. 1944. Measurement of bird populations. Lcological Monographs 14:67-106.

Lloyd J1), Doyle 1. 2011. Abundance and population trends of mangrove landbirds in southwest Florida. Journal of Ficld Ornithology 82:132-139.

I loyd JD, Slater GI. 2011. Influence of firc and water regimes on pineland bird assemblages. Natural Areas Joumal 31:270 282.

Lloyd JD, Slater GL. 2012. lire history and the structure of pine rockland bird assemblages. Natural Areas Journal 32:247-259.

Lugo AL, Patterson-Zucca C. 1977. The impact of low temperature stress on mangrove structure and growth. Tropical Fcology 18 149-161

Iugo AE, Sncdaker SC. 1974. The ccology of mangroves. Annua Review of Lcology and Systematics 5:39 64.

Luther 1), Greenberg R. 2011. 'The island syndrome in coastal wetland ecosystems: convergent evolution of large bills in mangrove passerines. Auk 128:201-204

MacArthur RH, Diamond JM, Karr JR, 1972. Density compensation in island faunas. Ecology 53:330-342.

MacArthur RH, Wilson EO. 1963. An cquilibrium theory of insular zoogeography. Lvolution 17:373-387.

McGrady-Steed J. Morin PJ. 2000. Biodiversity, density compensation, and the dynamics of populations and functional groups. Fcology 81:361-373

McNair DB. 1991. Copulation in the mangrove cuckoo (Coccyzus minor). Florida Ficld Naturalist 19:84-85.

Nichols JD, Hines JE, Sauer JR, Fallon FW, Fallon JF, Heglund PJ. 2000. A double-observer approach for estimating detection probability and abundance from point counts. Auk 117:393 408 .

Nichols JD, Thomas L, Conm PB. 2009. Inference about landbird abundance from count data: recent advances and future dircctions. Pagcs 201-235 in Thompson DI, Cooch FG,
Conroy MJ, editors. Modeling demographic processes in marked populations. Ncw York: Springer.

Northrop J. 1891. The birds of Andros Island, Bahamas. Auk 8:64 80.

Noske R. 1996. Abundance, zonation and foraging ecology of bird in mangroves of Darwin Harbour, Northern Territory. Wildlife Rescarch 23:443-474.

Odum WE, Heald EJ. 1972. Trophic analyses of an cstuarinc mangrove community. Bulletin of Marinc Science 22:671-738.

Odum WE, Mclvor CC, Smith 111 1J. 1982. The ecology of the mangroves of South llorida: a community profile. Washington, D.C.: U.S. Fish and Wildlife Service, Office of Biological Services.

Pecr BD, Bollinger EK. 1997. Common grackle (Quiscalus quiscula). Account 271 in Poole A, editor. 'The birds of North America online. Ithaca, New York: Comell Lab of Ornithology. Available: http://bna.birds.comell.edu/bna/species/271 (l'ebruary 2014).

Penfound WT, Hathaway ES, 1938. Plant communitics in the marshlands of southcastern Iouisiana. Fcological Monographs 8:4-56.

de Pourtales Ll. 1877. Hints on the origin of the flora and fauna of the llorida Keys. American Naturalist 11:137-144.

Prather JW, Gruz. A. 1995. Brceding biology of Florida prairic warblers and Cuban ycllow warblers. Wilson Bulletin 107:475484.

Prather JW, Cruz A. 1996. Resource use and population densities of prairie and yellow warblers in an area of recent contact the lilorida Keys. Caribbean Journal of Science 32:399 405.

Prather JW, Cruz. A. 2002. Distribution, abundance, and brecding biology of potential cowbird hosts on Sanibcl Island, Florida. Florida Ficld Naturalist 30:21-76.

Prather JW, Cruz A. 2006. Breeding biology of red-winged blackbirds in South llorida. Southeastern Naturalist 5:547 554 .

R Development Core Team. 2010. R: a language and cnvironmen for statistical computing. Vicnna: R Foundation for Statistica Computing.

Rich 'ID, Beardmore CJ, Berlanga H, Blancher PJ, Bradstree MSW, Butcher GS, Demarest DW, Dunn LH, Hunter WC, Inigo-Llias LL, Kennedy JA, Martell AM, Panjabi AO, Pashley DN, Rosenberg KV, Rustay G.M, Wcndt JS, Will TC. 2004 Partncrs in Flight North American landbird conservation plan. Ithaca, Ncw York: Corncll Iab of Ornithology.

Robertson WB. 1955. An analysis of the breeding-bird population of tropical 1\%orida in relation to the vegetation. Doctoral dissertation. Urbana: University of Illinois.

Robertson WB. 1962. Obscrvations on the birds of St. John, Virgin Islands. Auk 79:44-76.

Robertson WB, Kushlan JA. 1974. 'The southern llorida avifauna. Pages 413-452 in Gleason PJ, editor. Environments of South llorida: present and past. Miami: Miami Geological Society, Miami.

Robertson WB Jr, Woolfenden GF. 1992. Florida bird species: an annotated list. Gaincsville, Florida: Florida Ornithologica Society.

Salgado-Ortiz J, Marra PP, Sillett 'TS, Robertson RJ. 2008. Breeding ecology of the mangrove warbler (Dendroica petechio bryanti) and comparative life history of the ycllow warbler subspccics complex. Auk 125:402-410.

Schwart7, A, Klinikowski RF, 1963. Obscrvations on West Indian birds. Proceedings of the Academy of Natural Sciences of Philadelphia 115:53-77

Scott W. 1888. A summary of observations on the birds of the Gulf Coast of Florida. Auk 6:373-379.

Shackelford CE, Brown RF, Comner RN. 2000. Red-bellicd woodpccker (Melanerpes carolinus). Account 500 in Poole A editor. The birds of North America online. Ithaca, New York: Cornell Lab of Ornithology. Available: hitp://bna.birds. comell.edu/bna/species/500. (lebruary 2014).

Sherrod CT, McMillan C. 1985. The distributional history and ccology of mangrove vegetation along the northern Gulf of Mexico coastal region. Contributions in Marine Science 28 $129-140$

Smith GA, Jackson JA. 2002. Gray kingbird (Tyrannus dominicensis) Account 668 in Poole A. editor. The birds of North America online. Ithaca, New York: Corncll Iab of Ornithology. Available: http://bna.birds.corncll.cdu/bna/spccics/668 (Fcbruary 2014). 
Sncdaker SC. 1989. Overvicw of ccology of mangroves and information necds for Florida Bay. Bulletin of Marinc Scicnce 44:341-347.

Stevenson HM. 1957. The relative magnitude of the trans-Gulf and circum-Gulf spring migrations. Wilson Bulletin 69:39-77.

Stevenson HM. Anderson BH. 1994. 'The birdlife of llorida. Gainesville: University Press of llorida.

Strong AM, Bancroft G'l'. 1994. Postledging dispersal of white-crowned pigcons: implications for conscrvation of deciduous seasonal forests in the Florida Keys. Conscrvation Biology 8:770-779.

Theobald DM, Stevens DI, White D, Urquhart NS, Olsen AR Norman JB. 2007. Using GIS to generate spatially-balanced random survey designs for natural resource applications. Linvironmental Management 40:134-146.

Toscano M, Macintyre IG. 2003. Corrected western Atlantic sealevel curve for the last 11,000 years based on calibrated $14 \mathrm{C}$ dates from Acropora palmata framework and intertidal mangrove peat. Coral Recfs 22:257-270.

U.S. Department of the Interior. 2005. Science plan in support of ecosystem restoration, preservation, and protection in South Horida. Washington, D.C.: U.S Department of Interior.

U.S. Fish and Wildlife Service. 1999. South llorida multi-species recovery plan. U.S Atlanta: Department of Interior, lish and Wildlife Service.

Watts WA. 1971. Postglacial and interglacial vegetation history of southern Gcorgia and central Florida. Ecology 52:676-690.
Watts WA. 1980. The late Quatemary vegetation history of the southcastern Unitcd States. Annual Revicw of Ecology and Systcmatics 11:387-409.

Watts W. Hansen B. 1994. Pre-Holocene and Holocene pollen records of vegetation history from the lilorida peninsula and their climatic implications. Palaeogeography, Palaeoclimatology, Palaeoecology 109:163-176.

White GC. 1992. PC SURVIV user's manual. Fort Collins: Colorado State University, Department of Fishery and Wildlife Biology.

Wicbe KI, Moore WS. 2010. Northern flicker (Colaptes auratus) Account 166a in Poolc A, cditor. The birds of North America online. Ithaca, New York: Comell Lab of Ornithology. Available: http://bna.birds.conell.edu/bna/species/166a (l'ebruary 2014).

Wiley JW, Wiley BN. 1979. The biology of the white-crowned pigcon. Wildlife Monographs 64:3-54.

Woolfenden, GE, Robertson Jr WB, 2006. Part I: sources and postsettlement changes. Pages $5-\overline{70}$ in Noss RF, cditor. The breeding birds of llorida. Gainesville, llorida: Llorida Ornithological Society.

Yasukawa K, Searcy WA. 1995. Red-winged blackbird (Agelaiu phoeniceus. Account 184 in Poole A, editor. The birds of North America online. Ithaca, Ncw York: Cornell Iab of Ornithology. Available: http://bna.birds.corncll.cdu/bna/species/184 (Fcbruary 2014). 